\title{
Effects of rhodomyrtone on Gram-positive bacterial tubulin homologue FtsZ
}

\author{
Dennapa Saeloh ${ }^{1,2}$, Michaela Wenzel ${ }^{3}$, Thanyada Rungrotmongkol ${ }^{4,5}$, Leendert Willem Hamoen $^{3}$, \\ Varomyalin Tipmanee ${ }^{\text {Corresp., }}{ }^{6}$, Supayang Piyawan Voravuthikunchai ${ }^{\text {Corresp. }}$ 1,2 \\ 1 Excellence Research Laboratory on Natural Products, Faculty of Science and Natural Product Research Center of Excellence, Prince of Songkla \\ University, Hat Yai, Thailand \\ 2 Department of Microbiology, Faculty of Science, Prince of Songkla University, Hat Yai, Thailand \\ 3 Bacterial Cell Biology, Swammerdam Institute for Life Sciences, University of Amsterdam, Amsterdam, Netherlands \\ 4 Department of Chemistry, Faculty of Science, Chulalongkorn University, Bangkok, Thailand \\ 5 Center of Innovative Nanotechnology, Chulalongkorn University, Bongkok, Thailand \\ 6 Department of Biomedical Science, Faculty of Medicine, Prince of Songkla University, Hat Yai, Thailand \\ Corresponding Authors: Varomyalin Tipmanee, Supayang Piyawan Voravuthikunchai \\ Email address: tvaromya@medicine.psu.ac.th, supayang.v@psu.ac.th
}

Rhodomyrtone, a natural antimicrobial compound, displays potent activity against many Gram-positive pathogenic bacteria, comparable to last-defence antibiotics including vancomycin and daptomycin. Our previous studies pointed towards effects of rhodomyrtone on the bacterial membrane and cell wall. In addition, a recent molecular docking study suggested that the compound could competitively bind to the main bacterial cell division protein FtsZ. In this study, we applied a computational approach (in silico), in vitro, and in vivo experiments to investigate molecular interactions of rhodomyrtone with FtsZ. Using molecular simulation, FtsZ conformational changes were observed in both (S)and $(R)$-rhodomyrtone binding states, compared with the three natural states of FtsZ (ligand-free, GDP-, and GTP-binding states). Calculations of free binding energy showed a higher affinity of FtsZ to (S)-rhodomyrtone $\left(-35.92 \pm 0.36 \mathrm{kcal} \mathrm{mol}^{-1}\right)$ than the GDP substrate $\left(-23.47 \pm 0.25 \mathrm{kcal} \mathrm{mol}^{-1}\right)$ while less affinity was observed in the case of (R)rhodomyrtone $\left(-18.11 \pm 0.11 \mathrm{kcal} \mathrm{mol}^{-1}\right)$. In vitro experiments further revealed that rhodomyrtone reduced FtsZ polymerization by $36 \%$ and inhibited GTPase activity by up to $45 \%$. However, the compound had no effect on FtsZ localization in Bacillus subtilis at inhibitory concentrations and cells also did not elongate after treatment. Higher concentrations of rhodomyrtone did affect localization of FtsZ and also affected localization of its membrane anchor proteins FtsA and SepF, showing that the compound does not specifically inhibit FtsZ but rather impairs multiple divisome proteins. Furthermore, a number of cells adopted a bean-like shape suggesting that rhodomyrtone possibly possesses further targets involved in cell envelope synthesis and/or maintenance. 
$4 \quad{ }^{1}$ Excellence Research Laboratory on Natural Products, Faculty of Science and Natural Product

5 Research Center of Excellence, Prince of Songkla University, Hat Yai, Songkhla (Thailand)

$6 \quad{ }^{2}$ Department of Microbiology, Faculty of Science, Prince of Songkla University, Hat Yai,

7 Songkhla (Thailand)

$8{ }^{3}$ Bacterial Cell Biology, Swammerdam Institute for Life Sciences, University of Amsterdam,

9 Amsterdam (the Netherlands)

$11{ }^{5}$ Center of Innovative Nanotechnology, Chulalongkorn University, Bangkok (Thailand)

$12{ }^{6}$ Department of Biomedical Sciences, Faculty of Medicine, Prince of Songkla University, Hat

13 Yai, Songkhla (Thailand)

14 Corresponding Authors: Supayang Piyawan Voravuthikunchai, supayang.v@psu.ac.th

$$
\text { Varomyalin Tipmanee, tvaromya@medicine.psu.ac.th }
$$

17 Abstract: Rhodomyrtone, a natural antimicrobial compound, displays potent activity against

18 many Gram-positive pathogenic bacteria, comparable to last-defence antibiotics including

19 vancomycin and daptomycin. Our previous studies pointed towards effects of rhodomyrtone on

20 the bacterial membrane and cell wall. In addition, a recent molecular docking study suggested

21 that the compound could competitively bind to the main bacterial cell division protein FtsZ. In

22 this study, we applied a computational approach (in silico), in vitro, and in vivo experiments to

23 investigate molecular interactions of rhodomyrtone with FtsZ. Using molecular simulation, FtsZ 
24 conformational changes were observed in both (S)- and (R)-rhodomyrtone binding states, 25 compared with the three natural states of FtsZ (ligand-free, GDP-, and GTP-binding states).

26 Calculations of free binding energy showed a higher affinity of FtsZ to (S)-rhodomyrtone (-35.92

$\left.27 \pm 0.36 \mathrm{kcal} \mathrm{mol}^{-1}\right)$ than the GDP substrate $\left(-23.47 \pm 0.25 \mathrm{kcal} \mathrm{mol}^{-1}\right)$ while less affinity was

28 observed in the case of $(\mathrm{R})$-rhodomyrtone $\left(-18.11 \pm 0.11 \mathrm{kcal} \mathrm{mol}^{-1}\right)$. In vitro experiments further

29 revealed that rhodomyrtone reduced FtsZ polymerization by $36 \%$ and inhibited GTPase activity

30 by up to $45 \%$. However, the compound had no effect on FtsZ localization in Bacillus subtilis at

31 inhibitory concentrations and cells also did not elongate after treatment. Higher concentrations of

32 rhodomyrtone did affect localization of FtsZ and also affected localization of its membrane

33 anchor proteins FtsA and SepF, showing that the compound does not specifically inhibit FtsZ but

34 rather impairs multiple divisome proteins. Furthermore, a number of cells adopted a bean-like

35 shape suggesting that rhodomyrtone possibly possesses further targets involved in cell envelope

36 synthesis and/or maintenance.

\section{Introduction}

39 Rhodomyrtone, extracted from Rhodomyrtus tomentosa leaves, displays potent activity against many Gram-positive bacteria including methicillin-resistant Staphylococcus aureus (MRSA)

41 (Limsuwan et al., 2009). The activity is comparable to that of the last-defence antibiotics, 42 vancomycin and daptomycin, and it is effective against recently emerging vancomycin43 intermediate $S$. aureus strains (Leejae et al., 2013). Thus, rhodomyrtone is an interesting new 44 antibiotic candidate to challenge drug-resistant bacterial infections. Prior to further evaluation of 45 its clinical potential, it is important to understand how it kills bacteria. Therefore, the molecular 46 targets of rhodomyrtone need to be identified. 
Despite several attempts to elucidate the mechanism of action of rhodomyrtone, its exact target has not yet been found. Proteomic and transcriptomic analyses of rhodomyrtone-treated MRSA pointed towards the cytoplasmic membrane and cell wall being affected (Sianglum et al., 2012; Sianglum et al., 2011; Visutthi et al., 2011). Similarly, abnormalities of both cell wall and cell membrane were revealed by transmission electron microscopy (Sianglum et al., 2011). However, a recent in silico screening for potential rhodomyrtone targets suggested that the compound could competitively bind to the main bacterial cell division protein FtsZ (Saeloh et al., 2016). Consequently, earlier studies showed that rhodomyrtone caused MRSA cells to slightly enlarge, did not exhibit bacteriolytic activity, and did not promote leakage of proteins out of cells (Leejae et al., 2013; Limsuwan et al., 2009). These occurrences were promoting the hypothesis that rhodomyrtone could indeed inhibit an intracellular target such as FtsZ (Adams et al., 2011; Kaul et al., 2013).

FtsZ, a homologue of eukaryotic tubulin, drives bacterial cell division by forming the constricting Z-ring (Pilhofer et al., 2011). To perform this task, the protein forms polymers, a process which is driven by its ability to hydrolyse GTP to GDP (GTPase activity). Following polymerization of FtsZ into the Z-ring, the membrane and cell wall constrict and form into a septum, which separates the two daughter cells (de Boer et al., 1992). Consequently, FtsZ disassembles and GDP is released from FtsZ, which is then ready to bind a new GTP molecule and polymerize again (Natarajan \& Senapati, 2013; Oliva et al., 2007). This process is essential for bacterial cytokinesis and FtsZ is essential in all bacteria. Conditional mutants defective in cell division elongate into filaments. Despite these promising features, cell division has not yet been exploited as an antibiotic target in the clinic. Therefore, FtsZ is an interesting target for new antibacterial drugs. 

research. In particular, a combination of bioinformatics tools and experimental methods have

72 been efficiently applied to uncover the mechanisms of effector molecules on their targets (Qiu et 73 al., 2013; Singh et al., 2014). Currently, molecular dynamic (MD) simulation, a common 74 computational technique used for studying proteins, is contributing to drug discovery and 75 development. This approach is able to provide information at atomic levels by calculating the interactions between ligands and receptors and predicting conformational changes in drug-

77 binding targets.

In order to analyse the inhibitory effects of rhodomyrtone on FtsZ in more detail, we used MD simulation to predict the interactions and impacts of the compound on the structure of FtsZ.

80 Using polymerization (light scattering) and GTPase activity assays, we found that rhodomyrtone

81 affected the function of purified FtsZ. Fluorescence light microscopy finally gave insights into 82 the effect of rhodomyrtone on FtsZ in live bacteria.

\section{Materials and Methods}

\section{Preparation of structures}

In this study, we investigated the structure of FtsZ bound to various ligands as well as ligand-free

87 FtsZ using molecular dynamics simulation. The preparation of the FtsZ starting coordinates was carried out using GDP-FtsZ from Staphylococcus aureus, (PDB entry 3VOA) as a molecular

89 template. First, co-crystallized GDP in the structure was removed to obtain a ligand-free FtsZ

90 starting structure. GDP, GTP, (S)-rhodomyrtone and (R)-rhodomyrtone were docked to the

91 ligand-free FtsZ protein in a molecular docking approach. GDP and GTP bound to FtsZ

92 mimicked an in vivo state in S. aureus (Matsui et al., 2012) while both enantiomers of 
93 rhodomyrtone were used for assaying drug-target interaction with FtsZ. Since the structures of

94 GTP and rhodomyrtone were artificial, ligand Cartesian coordinates were constructed and

95 energy-minimized using ArgusLab 4.0.1 software (Thompson, 2004). Ligand-FtsZ complexes

96 were created by molecular docking. Docking studies were carried out using the Autodock4

97 package (Morris et al., 2009) to predict the most convenient conformation and ligand position

98 bound to the protein. A grid box of $110 \AA$ x $110 \AA$ x $110 \AA$ with a grid spacing of $0.375 \AA$ was

99 established in the center of a macromolecule. A ligand was regarded to be a flexible molecule in

100 search of the best position in the grid space of the rigid protein. Fifty independent docking jobs,

101 each consisting of 200 runs, were conducted with a Lamarckian genetic algorithm employed with

102 default parameters. A docked complex structure was chosen on the basis of the lowest binding

103 energy. Finally, the five structures (GDP-FtsZ, GTP-FtsZ, (S)-rhodomyrtone-FtsZ, (R)-

104 rhodomyrtone-FtsZ and ligand-free FtsZ) were obtained to initiate molecular dynamic

105 simulation.

106

107 Molecular dynamic simulation

108 Molecular dynamics of the above-mentioned FtsZ forms were conducted using the AMBER12

109 package (Gohlke et al.) to observe ligand-induced conformational changes of FtsZ as well as the

110 binding energy in dynamic conditions. Firstly, molecular information of both enantiomeric forms

111 of rhodomyrtone, such as RESP atomic charges and bond parameters, was deducted from an

112 optimized structure. Geometry optimizations and electrostatic charge calculations were

113 performed using Gaussian 03 (Gaussian Inc., Wallingford, CT), and RESP charges were

114 automatically generated using an antechamber program (Gohlke et al., 2003). Atomic charges of

115 GDP and GTP were directly adopted from previous studies (Bayly et al., 1993). Regarding the 
116 FtsZ structure, the protonation states of all ionisable amino acid side chains were calculated at

$117 \mathrm{pH}$ 7. In His 10, a hydrogen at the side chain was located at the $\varepsilon$-nitrogen atom, and no doubly

118 protonated histidine was applied in the FtsZ structure following (Natarajan \& Senapati, 2013).

119 Missing hydrogen atoms were added by a leap program. All five protein complexes were

120 solvated by a pre-equilibrated TIP3P water rectangular box with an edge of $12 \AA$. Potassium $\left(\mathrm{K}^{+}\right)$

121 and chloride $\left(\mathrm{Cl}^{-}\right)$ions were added, yielding $150 \mathrm{mM}$ of $\mathrm{KCl}$ solution. The system was energy-

122 minimized for 2000 steps using the steepest descent algorithm to remove improper van der

123 Waals contacts, and continued with a 500 ps canonical (NVT) ensemble at a temperature of 310

$124 \mathrm{~K}\left(37^{\circ} \mathrm{C}\right)$ using a time step of 1 fs. Harmonic potential was applied in the NVT simulation for

125 positional restraint of the protein and ligand, using force constants of 200, 100, 50, 25, and 10

$126 \mathrm{kcal} \mathrm{mol}^{-1} \AA^{-2}$ in each $100 \mathrm{ps}$, respectively. After $500 \mathrm{ps}$, the restraint on the protein and ligand

127 components was released and the system was switched into an isobaric-isothermal (NPT)

128 simulation at a constant pressure of $1 \mathrm{~atm}$, and $310 \mathrm{~K}$ with a time step of $2 \mathrm{fs}$ for $150 \mathrm{~ns}$. In the

129 NVT simulation, the temperature was controlled by a Langevin thermostat (Allen \& Tildesley,

130 1989), while in the NPT simulation, the temperature and pressure were regulated using a weak-

131 coupling algorithm (Berendsen et al., 1984). Finally, 1000 snapshots from the last 50 ns of NPT

132 trajectory were used to compute a configuration average and structural analysis.

133

134 Binding free energy analysis

135 To evaluate the relative binding affinity of rhodomyrtone to FtsZ, the Molecular

136 Mechanics/Poisson Boltzmann Surface Area (MM/PBSA) approach (Kollman et al., 2000;

137 Srinivasan et al., 1998) was chosen. In brief, the relative binding free energy ( $\Delta \mathrm{G})$ can be 
138 computed from energetic differences as follows (Genheden \& Ryde, 2015; Homeyer \& Gohlke,

139 2012; Wang et al., 2006):

$$
\Delta \mathrm{G}=\mathrm{G}_{\mathrm{LR}}-\mathrm{G}_{\mathrm{L}}-\mathrm{G}_{\mathrm{R}}
$$

$$
G_{L R}, G_{L} \text { and } G_{R} \text { represent the free energy components of the ligand-receptor complex, }
$$

142 ligand, and receptor respectively. The free energy of each state was derived from molecular

143 mechanics energy, broken down into:

$$
\mathrm{G}=\mathrm{E}_{\mathrm{bond}}+\mathrm{E}_{\mathrm{el}}+\mathrm{E}_{\mathrm{vdW}}+\mathrm{E}_{\mathrm{npl}}+\mathrm{E}_{\mathrm{pol}} \text {. }
$$

In the equation, all variables can be described: $\mathrm{E}_{\mathrm{bond}}, \mathrm{E}_{\mathrm{el}}$, and $\mathrm{E}_{\mathrm{vdw}}$ are the $\mathrm{MM}$ energy values from the bonding terms (bond, angle, and dihedral), electrostatic, and van der Waals interactions, whereas $\mathrm{E}_{\mathrm{npl}}$ and $\mathrm{E}_{\mathrm{pol}}$ are the nonpolar and polar contributions due to solvent solvation energy (Genheden \& Ryde, 2015).

Since in this study all simulations were carried out using an MD trajectory, binding free energy was reported to be a configuration average $\langle\Delta \mathrm{G}\rangle$, obtained through the formula

$$
\left.\langle\Delta \mathrm{G}\rangle=\left\langle\mathrm{G}_{\mathrm{LR}}-\mathrm{G}_{\mathrm{L}}-\mathrm{G}_{\mathrm{R}}\right)\right\rangle .
$$
concentration on 5000 equidistant snapshots from a 100-150 ns MD trajectory. The calculation was performed using a Python script (MMPBSA.py) implemented in an AMBER12 package. The total binding free energy of the ligands (rhodomyrtone and GDP) as well as their energy contribution determined and were used to assess the binding affinity of the ligand to FtsZ.

\section{Purification of rhodomyrtone}

159 Rhodomyrtone was isolated from leaves of Rhodomyrtus tomentosa by extraction with 95\%

160 ethanol as described by our group (Hiranrat \& Mahabusarakam, 2008; Limsuwan et al., 2009). 
161 Purity of rhodomyrtone was confirmed by nuclear magnetic resonance (NMR) and mass

162 spectrometry (MS) (Hiranrat \& Mahabusarakam, 2008; Salni et al., 2002). Purified

163 rhodomyrtone was dissolved in dimethyl sulfoxide (DMSO, Merck, Germany) before use.

\section{Purification of FtsZ}

166 Calcium-competent Escherichia coli BL21 (DE3) cells were freshly transformed with the 167 plasmids pCXZ and pBS58 for co-expression of untagged B. subtilis FtsZ with E. coli FtsQAZ,

168 the latter helping $E$. coli to survive stress induced by overexpression of the $B$. subtilis protein 169 (Wang \& Lutkenhaus, 1993). Colonies were selected on Luria-Bertani (LB) agar plates 170 supplemented with $50 \mu \mathrm{g} / \mathrm{mL}$ ampicillin (Sigma-Aldrich) and $50 \mu \mathrm{g} / \mathrm{mL}$ spectinomycin (Sigma-

171 Aldrich). Overnight cultures inoculated with a single transformant colony were diluted 1:100 in

172 fresh antibiotic-containing $\mathrm{LB}$ medium. $6 \mathrm{~L}$ of culture were grown at $37^{\circ} \mathrm{C}$ to an $\mathrm{OD}_{600 \mathrm{~nm}}$ of 0.4 173 and induced with $1 \mathrm{mM}$ IPTG (Sigma-Aldrich) for $4 \mathrm{~h}$. Cultures were quickly cooled on slush 174 ice, harvested by centrifugation, and washed once in $50 \mathrm{mM}$ Tris $\mathrm{pH} 7.5,100 \mathrm{mM} \mathrm{NaCl}, 1 \mathrm{mM}$ 175 EDTA (Sigma-Aldrich). The dry cell pellet was flash frozen in liquid nitrogen and stored at $17680^{\circ} \mathrm{C}$ until further use. The pellet was dissolved in $60 \mathrm{~mL} 50 \mathrm{mM}$ Tris $\mathrm{pH} 8.0,50 \mathrm{mM} \mathrm{KCl}, 1$ $177 \mathrm{mM}$ EDTA, $10 \mathrm{mM} \mathrm{MgCl} 2,1 \mathrm{mg} / \mathrm{mL}$ DNase (Sigma-Aldrich), and 1 complete mini protease 178 inhibitor tablet (Roche). The cells were disrupted by French Press and cell debris was removed 179 by centrifugation $(200,000 \mathrm{x} \mathrm{g}, 1 \mathrm{~h})$. The supernatant was subjected to ammonium sulfate 180 precipitation as follows. $26.4 \mathrm{~mL}$ of a saturated ammonium sulfate solution were added drop by 181 drop under continuous stirring at $4^{\circ} \mathrm{C}$, followed by further stirring for $20 \mathrm{~min}$. Precipitated 182 proteins were removed by centrifugation $(30,000 \mathrm{x} \mathrm{g}, 30 \mathrm{~min})$ and the FtsZ-containing 183 supernatant was subjected to a second precipitation step by adding $9.5 \mathrm{~mL}$ of saturated 
184 ammonium sulfate solution as described above. After 10 min of stirring, the FtsZ was spun down $185(30,000 \times \mathrm{g}, 30 \mathrm{~min})$ and the pellet was dissolved in $45 \mathrm{~mL} 50 \mathrm{mM}$ MES-KOH pH 6.5, $5 \mathrm{mM}$ $186 \mathrm{MgCl}_{2}$ (buffer A), followed by ion exchange chromatography. The sample was loaded onto a 5 187 mL HiTrap Q HP column (GE Healthcare) equilibrated with 3 column volumes of buffer A. The 188 column was washed with buffer A until reaching a stable baseline, followed by washing with 5\% 189 buffer B (50 mM MES-KOH pH 6.5, $\left.5 \mathrm{mM} \mathrm{MgCl}_{2}, 1 \mathrm{M} \mathrm{KCl}\right)$. After reaching a stable baseline 190 again, FtsZ was eluted in a gradient up to $50 \%$ buffer B over 5 column volumes. FtsZ-containing

191 fractions were pooled and concentrated with $10 \mathrm{kDa}$ molecular weight cutoff filters (Amicon), if 192 necessary. Glycerol was added to a final concentration of $10 \%$ prior to flash freezing. Samples 193 were stored as single-use aliquots until further use.

\section{FtsZ polymerization in vitro}

196 FtsZ polymerization was monitored by $90^{\circ}$ light scattering. FtsZ $(10 \mu \mathrm{M})$ was added in a Tris 197 buffer (pH 7.4, $200 \mathrm{mM} \mathrm{KCl}$, and $1 \mathrm{mM}$ EDTA) in the absence (1\% DMSO as a control) or 198 presence of $10 \mu \mathrm{M}$ rhodomyrtone, $20 \mu \mathrm{M}$ rhodomyrtone, or $20 \mathrm{mM}$ 3-methoxy-benzamide (3199 MBA, Sigma-Aldrich), respectively. FtsZ assembly was started by addition of $5 \mathrm{mM} \mathrm{MgCl}_{2}$ and $2001 \mathrm{mM}$ GTP and monitored by observing light scattering over $2 \mathrm{~min}$ in a cuvette chamber at $37^{\circ} \mathrm{C}$.

201 Measurements were performed with a PTI fluorometer operated under the control of FeliX32 202 software. Both the excitation and emission wavelengths were set at $350 \mathrm{~nm}$ and a slit width of 4 203 nm was used.

204 To visualise FtsZ filaments, $5 \mu \mathrm{l}$ of sample were withdrawn immediately after starting the 205 reaction and diluted 1:5 in the same buffer additionally containing $10 \%$ polyethylen glycol 206 (Sigma-Aldrich) as a crowding agent. FtsZ filaments were visualised after 2 min of incubation at 
$20730^{\circ} \mathrm{C}$ using a Nikon Eclipse Ti microscope equipped with a CFI Plan Apochromat DM 100x oil 208 objective, an Intensilight HG 130 W lamp, a C11440-22CU Hamamatsu ORCA camera, and 209 NIS-Elements software, version 4.20.01.

\section{Determination of GTPase activity}

212 The GTPase activity of FtsZ was analyzed using a malachite green/ammonium molybdate assay 213 as described by Bharat et al. (Bharat et al., 2013) with a minor modification. FtsZ (10 $\mu \mathrm{M})$ was 214 incubated without or with different concentrations of rhodomyrtone $(5 \mu \mathrm{M}, 10 \mu \mathrm{M}$, and $20 \mu \mathrm{M})$ 215 and 3-MBA (5 mM, $10 \mathrm{mM}$, and $20 \mathrm{mM})$ in $50 \mathrm{mM}$ Tris buffer (pH 7.4) containing $200 \mathrm{mM}$

$216 \mathrm{KCl}$ and $1 \mathrm{mM} \mathrm{EDTA}$ at $37^{\circ} \mathrm{C}$ for $10 \mathrm{~min}$. The hydrolysis reaction was initiated by addition of 5 $217 \mathrm{mM} \mathrm{MgCl} 2$ and $1 \mathrm{mM} \mathrm{GTP}$. After 5 min of incubation, $\mathrm{HClO}_{4}(10 \% \mathrm{v} / \mathrm{v})$ was added to quench 218 the reaction. $100 \mu \mathrm{l}$ of each sample was transferred to a 96-well plate, mixed and incubated with $21940 \mu 1$ of reaction agent for 2 min. Released inorganic phosphates were monitored by measuring 220 the absorbance at $600 \mathrm{~nm}$. The amount of released phosphate was calculated using a phosphate 221 standard curve prepared with $\mathrm{KH}_{2} \mathrm{PO}_{4}$.

222

\section{Fluorescence microscopy}

224 To investigate the effect of the compound on Z-ring formation, FtsA, and MinD localization in 225 living cells, B. subtilis 874 (Weart et al., 2005) expressing green fluorescent protein (GFP)226 tagged FtsZ, PG62 (Gamba et al., 2009) expressing FtsA fused to yellow fluorescent protein 227 (YFP), and 4181 (Hamoen et al., 2006) expressing gfp-sepF were grown overnight in LB broth 228 at $30^{\circ} \mathrm{C}$ in the presence of $50 \mu \mathrm{g} / \mathrm{mL}$ spectinomycin (Sigma-Aldrich). The overnight culture was 229 diluted 1:100 into LB containing 0.5\% xylose (FtsZ), 0.15\% xylose (SepF), or $0.1 \mathrm{mM}$ isopropyl 
$230 \beta$-D-1-thiogalactopyranoside (IPTG) (FtsA) to induce expression of GFP or YFP fusion proteins,

231 and incubated at $30^{\circ} \mathrm{C}$ until an $\mathrm{OD}_{600 \mathrm{~nm}}$ of 0.3 . The cultures were then treated with $1 \mathrm{xMIC}(0.5$

$232 \mu \mathrm{g} / \mathrm{mL}, 1.13 \mu \mathrm{M}), 2 \mathrm{xMIC}(1 \mu \mathrm{g} / \mathrm{mL}, 2.26 \mu \mathrm{M})$, and $4 \mathrm{xMIC}(2 \mu \mathrm{g} / \mathrm{mL}, 4.52 \mu \mathrm{M})$ of

233 rhodomyrtone, 4x MIC (2 mg/mL, $13.23 \mu \mathrm{M})$ of 3-MBA, $100 \mu \mathrm{M} \mathrm{CCCP} \mathrm{(Sigma} \mathrm{Aldrich),} \mathrm{and}$

$2341 \%$ DMSO as a negative control. At various time pionts after treatment, samples were placed

235 onto $1 \%$ agarose slides and images were taken using a Nikon Eclipse Ti microscope as specified 236 above.

\section{Morphological changes observed with phase-contrast microscopy}

B. subtilis 168 (Anagnostopoulos \& Spizizen, 1961) overnight cultures were diluted 1:100 in

fresh LB and aerobically grown at $37^{\circ} \mathrm{C}$ until an $\mathrm{OD}_{600 \mathrm{~nm}}$ of 0.3 . Then the cultures were split-

241 treated with $1 \mathrm{xMIC}(0.5 \mu \mathrm{g} / \mathrm{mL}, 1.13 \mu \mathrm{M}), 2 \mathrm{xMIC}(1 \mu \mathrm{g} / \mathrm{mL}, 2.26 \mu \mathrm{M})$, and $4 \mathrm{xMIC}(2 \mu \mathrm{g} / \mathrm{mL}$,

$2424.52 \mu \mathrm{M})$ of rhodomyrtone, $1 \times \mathrm{xMIC}(0.5 \mathrm{mg} / \mathrm{mL}, 1.13 \mu \mathrm{M}), 2 \times \mathrm{MIC}(1 \mathrm{mg} / \mathrm{mL}, 2.26 \mu \mathrm{M})$, and

$2434 \mathrm{xMIC}(2 \mathrm{mg} / \mathrm{mL}, 13.23 \mathrm{mM})$ of 3-MBA, and $1 \%$ DMSO as a negative control. After $1 \mathrm{~h}, 2 \mathrm{~h}$,

244 and $4 \mathrm{~h}$ of incubation, samples were placed onto $1 \%$ agarose slides and imaged with an Olympus

245 BX60 microscope equipped with a Photometrics CoolSNAP fx digital camera. Images were 246 analyzed with Image J.

248 Results

249 Conformational changes of Apo, GDP-, GTP-FtsZ in complex with (S)-rhodomyrtone and 250 (R)-rhodomyrtone

251 To get insights into the molecular interactions of rhodomyrtone with FtsZ, we compared the 252 structures of FtsZ bound to rhodomyrtone, in both its (R)- and (S)-enantiomeric forms (Figure 1), 
253 with the natural states of FtsZ, namely the nucleotide-free and two nucleotide-bound forms (GDP 254 and GTP). An FtsZ crystal structure from S. aureus (Matsui et al., 2012) (PDB code 3VOA with 255 a resolution of $1.73 \AA$ ) was used as the representative of FtsZ. Molecular docking was employed 256 to identify the most favorable position of the respective ligands, namely GDP, GTP, (S)257 rhodomyrtone, and (R)-rhodomyrtone, upon interactions with FtsZ. A ligand-free protein was 258 set as a ligand-free-form (apo-form). MD simulations were assessed by Amber12 Force Field for $259150 \mathrm{~ns}$, and root mean square distances (rmsd) of backbone atoms compared to the starting 260 conformations were computed to analyze structural changes. Figure 2 illustrates that all systems 261 approached an equilibrium after $50 \mathrm{~ns}$ and remained constant from around $100 \mathrm{~ns}$. Thus, we 262 selected the last 50 runs to determine the average rmsds of FtsZ in the apo-, GDP-, and GTP263 bound forms, which were found to be $1.89,1.85$, and $2.20 \AA$, respectively. The values of all three 264 states did not differ significantly, implying structural similarity among FtsZ forms in all states.

265 Small variations are known to occur between monomer structures of apo-FtsZ, GDP-FtsZ, and 266 GTP-FtsZ across various bacterial species and nucleotide-binding states (Hsin et al., 2012). (R)-

267 rhodomyrtone-FtsZ and (S)-rhodomyrtone-FtsZ were found with rmsd values of 1.68 and 2.58 $268 \AA$, respectively.

269 To elucidate conformational changes in each region of the simulated proteins, time270 averaged structures were created and compared with the starting crystal conformation (Figure 271 3A). None of the averaged structures displayed significant conformational changes. Ligand-free 272 FtsZ (Figure 3B) appeared similar in overview; however, the loop T3 and loop T7 regions were 273 slightly different from the original structure. The structural changes in the GDP- and GTP274 binding states (Figures 3C-D) showed changes in loop H6 and loop H7, with this loop bent 275 towards the substrate binding pocket. Loop H6 and loop H7 are important for binding one FtsZ 
276 monomer to another to finally form FtsZ filaments (Matsui et al., 2014). Therefore,

277 conformational changes in this region may reflect FtsZ polymerization. The average structures of

278 the (S)-rhodomyrtone and (R)-rhodomyrtone binding states exhibited differences in terms of

279 their binding positions. The (S)-rhodomyrtone binding state (Figure 3E), in which the compound

280 was located in the same region as the natural substrate, showed an alteration in the substrate

281 binding pocket at loop T4. While the loop moved into the pocket, the helix H7 tilted away from

282 the original structure, resulting in opening of the binding pocket. Additionally, in the (S)-

283 rhodomyrtone state, we observed differences from the GDP- and GTP-binding states in loop H6

284 and loop H7. The changes in this pocket area might influence the S7-S10 region, harboring the

285 hydrolase domain. Surprisingly, although the (R)-rhodomyrtone binding site is located in the

286 GTPase domain, no obvious structural alterations were observed (Figure 3F).

287

288 Calculation of free binding energy

289 To estimate effective binding energy, energetic analysis was performed using the Molecular

290 Mechanics/Poisson Boltzmann Surface Area (MM/PBSA) method as summarized in Table 1.

291 Electrostatic forces significantly contributed to the binding of GDP to FtsZ as evidenced by the

292 strong interaction between the beta-phosphate of GDP and arginine (Arg135) at the binding site.

293 Nonpolar interactions played a crucial role in binding (S)-rhodomyrtone to the FtsZ protein. In

294 the simulated model (Figure 4A), (S)-rhodomyrtone interacts with a phenylalanine residue in a

295 hydrophobic pocket of FtsZ, which could be observed between the N-base aromatic ring of GDP

296 and aromatic residues of FtsZ (Huecas et al., 2015). This implies that an aromatic ring of (S)-

297 rhodomyrtone could interact with phenylalanine via $\pi-\pi$ stacking (Figure 4B). The total free

298 binding energies of the GDP, (S)-rhodomyrtone, and (R)-rhodomyrtone-FtsZ complexes were - 
$29923.47 \pm 0.25,-35.92 \pm 0.36$, and $-18.11 \pm 0.11 \mathrm{kcal} \mathrm{mol}^{-1}$, respectively. These values reflect a

300 higher affinity of FtsZ to (S)-rhodomyrtone than the GDP substrate. Interestingly, less affinity

301 was observed in the case of (R)-rhodomyrtone.

302

303 Molecular dynamics of the ligand-FtsZ states

304 To observe motion in each FtsZ region, root-mean-square fluctuations (rmsf) were computed

305 from trajectories of the last $50 \mathrm{~ns}$ simulations. Rmsf (Figure 5) indicates the flexibility of each

306 amino acid residue in the protein (307 amino acids). Several regions of ligand-free FtsZ, such as

307 T3, T5, H6-10, and S9-10, have been reported to be more flexible than GDP or GTP-bound

308 states (Natarajan \& Senapati, 2013). The FtsZ structure can generally be divided into two major

309 parts separated by H6-7 helices: (i) a nucleotide binding region, and (ii) a region responsible for

310 hydrolyzing the nucleotide bound to the neighboring FtsZ molecule (Hurley et al., 2016). The

311 rmsf values in the GDP- and GTP-binding states differed in the nucleotide binding area and the

312 H1, T4, and H6-8 regions. Smaller rmsf values in the GTP-binding state imply less flexibility of

313 the protein structure. The reduced plasticity of the GTP-binding states may be due to binding of

314 its gamma-phosphate to FtsZ, possibly leading to a straight filament formation in contrast to the

315 normally curved filaments induced by hydrolysis of GTP to GDP (Hsin et al., 2012). The state of

316 (S)-rhodomyrtone, bound to FtsZ in its nucleotide binding region, exhibited rmsf values close to

317 the values of the GDP- and GTP-binding states at loop T3, which is the binding site of the

318 nucleotide. Interestingly, loops T4 and T5 of the (S)-rhodomyrtone binding state were more

319 flexible than those of both nucleotide binding states. The results indicate that (S)-rhodomyrtone

320 might affect FtsZ assembly dynamics. In contrast, the flexibility pattern in the (R)-

321 rhodomyrtone-bound state was similar to that of ligand-free FtsZ (Supplementary Figure S1). 
322 This finding further supports the interaction analysis, presented in Table 1, suggesting that the

323 (R)-enantiomer of rhodomyrtone displays weaker binding to FtsZ. The dynamic behaviour of

324 (R)-rhodomyrtone-bound FtsZ was not different from the ligand-free protein. Our findings

325 suggest an enantiomeric specificity of rhodomyrtone towards the FtsZ protein.

326

327 In vitro effects of rhodomyrtone on FtsZ

328 We further investigated the effects of rhodomyrtone on FtsZ in vitro and in vivo. To this end, we used B. subtilis, a Gram-positive model organism for the study of cell division (Pinho et al.,

330 2013). B. subtilis FtsZ shares $70 \%$ amino acid sequence homology with $S$. aureus protein, in line

331 with studies on other compounds (Mathew et al., 2011; Sass et al., 2011). Rhodomyrtone was

332 highly active against both organisms. We performed $90^{\circ}$ angle light scattering and phase-contrast

333 microscopy using purified $B$. subtilis FtsZ. Rhodomyrtone, a natural compound containing (S)-

334 rhodomyrtone and (R)-rhodomyrtone, reduced FtsZ assembly in a concentration-dependent

335 manner by maximally 36\%. Meanwhile, 3-MBA, a stabilizer of FtsZ polymers (Adams et al.,

336 2011), enhanced polymerization by $16 \%$ (Figure 6A). This is in line with our in silico data

337 suggesting competitive binding to the nucleotide binding pocket, which should reduce the 338 formation of filaments.

To confirm that rhodomyrtone only affected FtsZ bundling, instead of causing any

340 aberrant bundle formation or nonspecific aggregation of the protein, we examined the same

341 samples microscopically. We neither observed protein aggregation, nor any obvious differences

342 in the appearance of FtsZ bundles when exposed to rhodomyrtone or 3-MBA, compared with

343 FtsZ in 1\% DMSO (Figure 6B). It has to be noted that under our experimental conditions, 20

$344 \mathrm{mM}$ of 3-MBA were necessary to observe any effect in light scattering experiments. In contrast 
345 to some of its optimized derivatives, 3-MBA has been reported to be only a weak inhibitor of

346 FtsZ (Czaplewski et al., 2009; Ohashi et al., 1999) and rhodomyrtone in fact displays a better

347 binding energy and inhibitory constant to FtsZ than 3-MBA (Saeloh et al., 2016).

348 FtsZ assembly is dependent on GTPase activity (Mukherjee \& Lutkenhaus, 1998) and our

349 molecular docking studies suggested competitive binding of (R)-rhodomyrtone to the GTPase

350 domain. In addition, conformational changes in the GTPase domain were observed in (S)-

351 rhodomyrtone binding FtsZ. Therefore, we determined the effect of rhodomyrtone on GTPase

352 activity using malachite green. GTPase activity was decreased up to $45 \%$ in the presence of

353 rhodomyrtone, similar to the inhibition achieved with 3-MBA (Figure 7). In contrast, cephalexin,

354 an inhibitor of penicillin-binding proteins active at the cell division site, served as a negative

355 control and did not affect GTPase activity.

356 FtsZ polymers disassemble when nucleotide molecules cannot reach FtsZ (Arjes et al.,

357 2015). Due to better affinity of rhodomyrtone, it could be speculated that (S)-rhodomyrtone,

358 binding to the nucleotide binding site of FtsZ, can compete with GDP in a monomeric FtsZ,

359 thereby obstructing replacement of GTP and consequently reducing FtsZ assembly. In addtion, it

360 was found that the GTPase region was changed by (S)-rhodomyrtone, supporting the influence

361 on GTPase activity of FtsZ. Recently, several approaches have been undertaken to develop FtsZ

362 inhibitors, and most of the molecules targeting the substrate binding region have shown similar

363 effects on FtsZ assembly and GTPase activity (Schaffner-Barbero et al., 2011). However, we

364 have to consider that rhodomyrtone is a racemic mixture composed of (S)-rhodomyrtone and

365 (R)-rhodomyrtone. Therefore, this may cause partial effect on FtsZ.

366

367 In vivo effects on Z-ring formation 
368 We further investigated whether rhodomyrtone could affect FtsZ in B. subtilis in vivo. FtsZ and

369 its membrane anchor FtsA are the first proteins located at the middle of the cell and recruit other

370 proteins involved in cell division (Adams \& Errington, 2009). Therefore, mid-cell localization of

371 FtsZ is crucial for the cell division process. We microscopically examined the presence of Z-

372 rings at mid-cell using a GFP fusion to FtsZ. In the absence of antibiotics (Figures 8A-B), FtsZ

373 clearly localized at mid-cell. Treatment with 3-MBA (Figures 8C-D) resulted in rapid

374 perturbation of FtsZ localization into a number of foci. In contrast, treatment with rhodomyrtone

375 resulted in a diffuse cytosolic GFP signal. Importantly, this effect of rhodomyrtone on FtsZ

376 localization was not observed at inhibitory concentrations (Figures 8E-F), but only after $1 \mathrm{~h}$ of

377 treatment with $2 \mathrm{xMIC}$ (Figures $8 \mathrm{G}-\mathrm{H}$ ) or $30 \mathrm{~min}$ of treatment with $4 \mathrm{xMIC}$ (Figures $8 \mathrm{I}-\mathrm{J}$ ), a

378 concentration already causing cell lysis of $B$. subtilis. To examine whether rhodomyrtone

379 specifically affects the localization of FtsZ or other divisome proteins as well, we next tested its

380 effect on the localization of FtsA and SepF, two peripheral membrane proteins that anchor the Z-

381 ring to the membrane. Similarly to what was observed for FtsZ, FtsA was detached from the

382 membrane after either 60 min of treatment with $2 x$ MIC or 30 min of treatment with $4 x M I C$ of

383 rhodomyrtone (Figure 9E-H). SepF was already delocalized after only 10 min of treatment with

384 2xMIC of rhodomyrtone (Figure 10). 3-MBA had no effect on localization of either FtsA or

385 SepF (Figure 9I-J, Figure 10). Thus, in contrast to 3-MBA rhodomyrtone does not specifically

386 affect FtsZ but multiple divisome proteins.

387 Dissociation of FtsZ into the cytosol is regularly observed with compounds affecting the 388 membrane potential (Müller et al., 2016; Strahl \& Hamoen, 2010; Te Winkel et al., 2010). This

389 is because its membrane anchors FtsA and SepF require the membrane potential for membrane

390 binding (Strahl \& Hamoen, 2010). In line, treatment with the depolarizing ionophore CCCP 
391 resulted in delocalization of FtsZ (Figure 9B), FtsA (Figure 9C-D), and SepF (Figure 10).

392 Although delocalization of FtsZ and FtsA happened faster with CCCP, the ionophore caused the

393 same phenotype as high concentrations of rhodomyrtone. Furthermore, both FtsA and SepF are

394 considered reporter proteins for membrane depolarization (Strahl \& Hamoen, 2010), suggesting

395 that membrane dissociation of FtsZ caused by rhodomyrtone is due to delocalization of its

396 membrane anchors, which is mediated by impairment of the cytoplasmic membrane.

397

398 Morphological changes

399 If inhibition of cell division through delocalization of multiple divisome proteins is in fact the 400 principal mechanism of the compound, long-time treatment should result in cell elongation 401 (Hwang \& Lim, 2015; Schaffner-Barbero et al., 2011). Therefore, we examined the impact of 402 rhodomyrtone on B. subtilis morphology by phase contrast microscopy. 3-MBA-treated cells 403 were clearly longer than control cells while no cell elongation was observed with different 404 concentrations of rhodomyrtone (Table 2). Instead, many cells appeared shorter and thicker. 405 Interestingly, a number of cells adopted a bean-like shape (Figure 11), suggesting that 406 rhodomyrtone does not specifically inhibit cell division but might have additional cell envelope 407 targets.

410 Discussion

411 In this study, we investigated the potential of rhodomyrtone to interact with and inhibit the 412 essential cell division protein FtsZ. FtsZ, which has been found regulated in both transcriptome 
413 and proteome analyses of rhodomyrtone-treated S. aureus (Sianglum et al., 2012; Sianglum et

414 al., 2011), has recently been identified as a possible molecular target in a preceding in silico

415 study. This was corroborated by observation that $S$. aureus cells were slightly enlarged after 416 prolonged treatment with rhodomyrtone (Saeloh et al., 2016). Using molecular modeling, we 417 could show that rohodomyrtone most likely binds to the nucleotide binding pocket of FtsZ, 418 whereby (S)-enantiomer was more effective than (R)-enantiomer. Competitive binding of (S)419 rhodomyrtone to the GDP/GTP-binding site should result in inhibition of FtsZ polymerization. In 420 fact, in vitro experiments with purified FtsZ revealed that both polymerization and GTPase 421 activity were affected by rhodomyrtone. However, polymerization was only inhibited by $36 \%$ 422 while GTPase activity was reduced by maximally $45 \%$. It is possible that rhodomyrtone as we 423 used it, i.e. isolated from the natural source containing both (S)- and (R)-enantiomers, is not 424 optimally efficient in inhibiting FtsZ. A similar phenomenon was observed with citronellal 425 (Altshuler et al., 2013), a major component of Corymbia citriodora and Cymbopogon nardus 426 essential oils. (+)-citronellal caused disruption of animal and plant microtubules, while (-)427 citronellal did not. Similarly, the (R)-enantiomer of N-benzyl-3-sulfonamidopyrrolidine was 428 effective in inhibiting polymerization of E. coli FtsZ, whereas (S)-enantiomer did not have any 429 effect (Mukherjee et al., 2007). Moreover, the potency of small molecule FtsZ inhibitors was 430 shown to be improved by eliminating enantiomeric conversion (Stokes et al., 2013). Therefore, 431 future studies could rule out whether pure (S)-rhodomyrtone might be a more efficient inhibitor 432 of FtsZ.

433 Despite being able to inhibit FtsZ in vitro, rhodomyrtone did not specifically inhibit FtsZ 434 in B. subtilis in vivo. Localization of FtsZ was not affected by inhibitory rhodomyrtone 435 concentrations, showing that FtsZ is not the main in vivo target. The protein was dispersed in the 
436 cytosol after treatment with higher concentrations of rhodomyrtone. Similar effects are typically

437 observed with antibiotics that dissipate the membrane potential (Araújo-Bazán et al., 2016;

438 Müller et al., 2016; Strahl \& Hamoen, 2010; Te Winkel et al., 2016). This is because FtsZ is

439 anchored to the membrane by two peripheral membrane proteins, FtsA and SepF. Both proteins

440 require the membrane potential for membrane binding and delocalize into the cytosol upon its

441 dissipation, which in turn results in cytosolic dispersion of FtsZ (Strahl \& Hamoen, 2010). In

442 fact, we could show that rhodomyrtone, similarly to CCCP and in sharp contrast to 3-MBA, does

443 affect the localization of both FtsA and SepF as well, suggesting that the compound has a more

444 general effect on the divisome than specifically inhibiting FtsZ polymerization. Considering that

445 both FtsA and SepF are reporters for membrane depolarization (Strahl \& Hamoen, 2010), it is

446 likely that this is due to effects of rhodomyrtone on the cell membrane. However, it took longer

447 treatment times and supra-inhibitory concentrations of rhodomyrtone to achieve delocalization of

448 cell division proteins, showing that its mechanism must be different from ionophores like CCCP.

449 Furthermore, long-time treatment of $B$. subtilis with rhodomyrtone did not result in cell

450 elongation, which would be expected from an FtsZ inhibitor (Bhattacharya et al., 2013;

451 Duggirala et al., 2014). A recent microscopy study determined the cytological profile of FtsZ

452 inhibitors and identified at least three-fold cell elongation and either increased or decreased FtsZ

453 ring spacing as essential factors to identify an FtsZ inhibitor (Araújo-Bazán et al., 2016). Neither

454 of these was observed with rhodomyrtone. Instead, the compound led to bean-like cell

455 deformations, indicating that rhodomyrtone has other targets involved in cell envelope synthesis

456 or maintenance and does not specifically inhibit Z-ring formation. This is well in line with our

457 observation that membrane potential-sensitive peripheral membrane proteins are affected by the

458 compound, suggesting that it rather impairs cytoplasmic membrane function. In fact, 
459 fractionation experiments with $S$. aureus showed that rhodomyrtone is unable to cross the

460 cytoplasmic membrane barrier to reach the cytosol in the first $4 \mathrm{~h}$ of treatment but instead

461 accumulates in the cell debris (The data is not shown.). Thus, it is reasonable to assume that the

462 compound, although being able to inhibit FtsZ in vitro, does not reach this target in the in vivo

463 situation. Instead, it is likely that rhodomyrtone interacts with membrane or cell wall-bound

464 protein targets or with membrane or cell wall structural components, and delocalization of 465 divisome proteins is a result of this interaction. Thus, cell shape deformations could be due to 466 inhibition or de-regulation of cell wall synthesis enzymes such as penicillin-binding proteins or 467 proteins involved in regulation of this process such as autolysins. An earlier transcriptomic study 468 found upregulation of a number of genes encoding membrane or lipoproteins after treatment of 469 S. aureus with rhodomyrtone (Sianglum et al., 2012) suggesting that it might interfere with the 470 cytoplasmic membrane. In fact, it has recently been shown that daptomycin, which also leads to 471 cell shape deformations, affects the cell wall synthesis machinery by disturbing membrane 472 organization (Müller et al., 2016). However, the same transcriptome study as well as earlier 473 proteomic studies on rhodomyrtone-treated S. aureus (Sianglum et al., 2011; Visutthi et al., 474 2011) showed the absence of typical cell envelope stress responses as elicited by e.g. daptomycin 475 (Muthaiyan et al., 2008; Poole, 2012), indicating that the mode of action of rhodomyrtone is 476 profoundly different from other compounds. Elucidation of rhodomyrtone's effects on the 477 bacterial cell envelope will be investigated in future studies.

478

479 Conclusions

480 We show that rhodomyrtone does inhibit FtsZ in vitro, probably by interaction of (S)-enantiomer 481 with the nucleotide biding pocket. However, FtsZ is not the main in vivo target of the compound, 
482 which interferes with the localization of several divisome proteins and also seems to have an

483 impact on the synthesis and/or maintenance of the cell envelope.

484

485

486

Acknowledgements

487 The authors express gratitude to the Eclipse Computer Cluster, National Center for Genetic

488 Engineering and Biotechnology (BIOTEC), Thailand. V.T. would like to thank Mr David 489 Patterson of the International Affairs Office, Faculty of Medicine, Prince of Songkla University 490 for manuscript proofreading and language editing service.

491

492 References:

493 Adams DW, and Errington J. 2009. Bacterial cell division: assembly, maintenance and 494 disassembly of the $Z$ ring. Nature Reviews Microbiology 7(9):642-653. DOI $495 \quad 10.1038 /$ nrmicro2198.

496 Adams DW, Wu LJ, Czaplewski LG, and Errington J. 2011. Multiple effects of benzamide 497 498 antibiotics on FtsZ function. Molecular Microbiology 80(1):68-84. DOI 10.1111/j.13652958.2011.07559.x.

Allen MP, and Tildesley DJ. 1989. Computer simulation of liquids: Oxford University Press.

Altshuler O, Abu-Abied M, Chaimovitsh D, Shechter A, Frucht H, Dudai N, and Sadot E. 2013. Enantioselective effects of $(+)$-and $(-)$-citronellal on animal and plant microtubules. Journal of Natural Products 76(9):1598-1604. DOI 10.1021/np4002702.

Anagnostopoulos C, and Spizizen J. 1961. Requirements for transformation in Bacillus subtilis. Journal of Bacteriology 81(5):741.

Araújo-Bazán L, Ruiz-Avila LB, Andreu D, Huecas S, and Andreu JM. 2016. Cytological profile of antibacterial FtsZ inhibitors and synthetic peptide MciZ. Frontiers in Microbiology 7. DOI 10.3389/fmicb.2016.01558.

Arjes HA, Lai B, Emelue E, Steinbach A, and Levin PA. 2015. Mutations in the bacterial cell 509 division protein FtsZ highlight the role of GTP binding and longitudinal subunit 
510

511

512

513

514

515

516

517

518

519

520

521

522

523

524

525

526

527

528

529

530

531

532

533

534

535

536

537

538

539

540

interactions in assembly and function. BMC Microbiology 15(1):1-16. DOI 10.1186/s12866-015-0544-z.

Bayly CI, Cieplak P, Cornell W, and Kollman PA. 1993. A well-behaved electrostatic potential based method using charge restraints for deriving atomic charges: the RESP model. The Journal of Physical Chemistry 97(40):10269-10280. DOI 10.1021/j100142a004.

Berendsen HJ, Postma JPM, van Gunsteren WF, DiNola A, and Haak J. 1984. Molecular dynamics with coupling to an external bath. The Journal of Chemical Physics 81(8):3684-3690. DOI 10.1063/1.448118.

Bharat A, Blanchard JE, and Brown ED. 2013. A high-throughput screen of the GTPase activity of Escherichia coli EngA to find an inhibitor of bacterial ribosome biogenesis. Journal of Biomolecular Screening:1087057113486001. DOI 10.1177/1087057113486001.

Bhattacharya A, Jindal B, Singh P, Datta A, and Panda D. 2013. Plumbagin inhibits cytokinesis in Bacillus subtilis by inhibiting FtsZ assembly-a mechanistic study of its antibacterial activity. FEBS Journal 280(18):4585-4599. DOI 10.1111/febs.12429.

Czaplewski LG, Collins I, Boyd EA, Brown D, East SP, Gardiner M, Fletcher R, Haydon DJ, Henstock V, and Ingram P. 2009. Antibacterial alkoxybenzamide inhibitors of the essential bacterial cell division protein FtsZ. Bioorganic \& Medicinal Chemistry Letters 19(2):524-527. DOI 10.1016/j.bmcl.2008.11.021.

de Boer P, Crossley R, and Rothfield L. 1992. The essential bacterial cell-division protein FtsZ is a GTPase. Nature 359:254-256. DOI 10.1038/359254a0.

Duggirala S, Nankar RP, Rajendran S, and Doble M. 2014. Phytochemicals as inhibitors of bacterial cell division protein FtsZ: Coumarins are promising candidates. Applied Biochemistry and Biotechnology 174(1):283-296. DOI 10.1007/s12010-014-1056-2.

Gamba P, Veening J-W, Saunders NJ, Hamoen LW, and Daniel RA. 2009. Two-step assembly dynamics of the Bacillus subtilis divisome. Journal of Bacteriology 191(13):4186-4194. DOI 10.1128/JB.01758-08.

Genheden S, and Ryde U. 2015. The MM/PBSA and MM/GBSA methods to estimate ligandbinding affinities. Expert Opinion on Drug Discovery 10(5):449-461. DOI 10.1517/17460441.2015.1032936. 
541 Gohlke H, Kiel C, and Case DA. 2003. Insights into protein-protein binding by binding free

542

543

544

545

546

547

548

549

550

551

552

553

554

555

556

557

558

559

560

561

562

563

564

565

566

567

568

569

570

571 energy calculation and free energy decomposition for the Ras-Raf and Ras-RalGDS complexes. Journal of Molecular Biology 330(4):891-913. DOI 10.1016/S00222836(03)00610-7.

Hamoen LW, Meile JC, De Jong W, Noirot P, and Errington J. 2006. SepF, a novel FtsZ-interacting protein required for a late step in cell division. Molecular Microbiology 59(3):989-999. DOI 10.1111/j.1365-2958.2005.04987.x.

Hiranrat A, and Mahabusarakam W. 2008. New acylphloroglucinols from the leaves of Rhodomyrtus tomentosa. Tetrahedron

64(49):11193-11197.

DOI 10.1016/j.tet.2008.09.054.

Homeyer N, and Gohlke H. 2012. Free energy calculations by the molecular mechanics Poisson- Boltzmann surface area method. Molecular Informatics 31(2):114-122. DOI 10.1002/minf.201100135/full.

Hsin J, Gopinathan A, and Huang KC. 2012. Nucleotide-dependent conformations of FtsZ dimers and force generation observed through molecular dynamics simulations. Proceedings of the National Academy of Sciences 109(24):9432-9437. DOI 10.1073/pnas.1120761109.

Huecas S, Marcelo F, Perona A, Ruiz-Ávila LB, Morreale A, Cañada FJ, Jiménez-Barbero Js, and Andreu JM. 2015. Beyond a fluorescent probe: inhibition of cell division protein FtsZ by mant-GTP elucidated by NMR and biochemical approaches. ACS Chemical Biology 10(10):2382-2392. DOI 10.1021/acschembio.5b00444.

Hurley KA, Santos TM, Nepomuceno GM, Huynh V, Shaw JT, and Weibel DB. 2016. Targeting the bacterial division protein FtsZ. Journal of Medicinal Chemistry. DOI 10.1021/acs.jmedchem.5b01098.

Hwang D, and Lim Y-H. 2015. Resveratrol antibacterial activity against Escherichia coli is mediated by Z-ring formation inhibition via suppression of FtsZ expression. Scientific Reports 5. DOI 10.1038/srep10029.

Kaul M, Zhang Y, Parhi AK, LaVoie EJ, Tuske S, Arnold E, Kerrigan JE, and Pilch DS. 2013. Enterococcal and streptococcal resistance to PC190723 and related compounds: molecular insights from a FtsZ mutational analysis. Biochimie 95(10):1880-1887. DOI 10.1016/j.biochi.2013.06.010. 
572 Kollman PA, Massova I, Reyes C, Kuhn B, Huo S, Chong L, Lee M, Lee T, Duan Y, and

573

574

575

576

577

578

579

580

581

582

583

584

585

586

587

588

589

590

591

592

593

594

595

596

597

598

599

600

601

Wang W. 2000. Calculating structures and free energies of complex molecules: Combining molecular mechanics and continuum models. Accounts of Chemical Research 33(12):889-897. DOI 10.1021/ar000033j.

Leejae S. 2013. Rhodomyrtone: Structure Modifications and Study on Antibacterial Mechanisms. D. Phil. Thesis. Prince of Songkla University.

Leejae S, Taylor PW, and Voravuthikunchai SP. 2013. Antibacterial mechanisms of rhodomyrtone against important hospital-acquired antibiotic-resistant pathogenic bacteria. Journal of Medical Microbiology 62(1):78-85. DOI 10.1099/jmm.0.049205-0.

Limsuwan S, Trip EN, Kouwen TR, Piersma S, Hiranrat A, Mahabusarakam W, Voravuthikunchai SP, van Dijl JM, and Kayser O. 2009. Rhodomyrtone: A new candidate as natural antibacterial drug from Rhodomyrtus tomentosa. Phytomedicine 16(6):645-651. DOI 10.1016/j.phymed.2009.01.010.

Mathew B, Srivastava S, Ross LJ, Suling WJ, White EL, Woolhiser LK, Lenaerts AJ, and Reynolds RC. 2011. Novel pyridopyrazine and pyrimidothiazine derivatives as FtsZ inhibitors. Bioorganic \& Medicinal Chemistry 19(23):7120-7128. DOI 10.1016/j.bmc.2011.09.062.

Matsui T, Han X, Yu J, Yao M, and Tanaka I. 2014. Structural change in FtsZ induced by intermolecular interactions between bound GTP and the T7 loop. Journal of Biological Chemistry 289(6):3501-3509. DOI 10.1074/jbc.M113.514901.

Matsui T, Yamane J, Mogi N, Yamaguchi H, Takemoto H, Yao M, and Tanaka I. 2012. Structural reorganization of the bacterial cell-division protein FtsZ from Staphylococcus aureus. Acta Crystallographica Section D: Biological Crystallography 68(9):1175-1188. DOI 10.1107/S0907444912022640.

Morris GM, Huey R, Lindstrom W, Sanner MF, Belew RK, Goodsell DS, and Olson AJ. 2009. AutoDock4 and AutoDockTools4: Automated docking with selective receptor flexibility. Journal of Computational Chemistry 30(16):2785-2791. DOI $10.1002 /$ jcc. 21256.

Mukherjee A, and Lutkenhaus J. 1998. Dynamic assembly of FtsZ regulated by GTP hydrolysis. The EMBO Journal 17(2):462-469. DOI 10.1093/emboj/17.2.462. 
602 Mukherjee S, Robinson CA, Howe AG, Mazor T, Wood PA, Urgaonkar S, Hebert AM,

603

604

605

606

607

608

609

610

611

612

613

614

615

616

617

618

619

620

621

622

623

624

625

626

627

628

629

630

631

RayChaudhuri D, and Shaw JT. 2007. N-Benzyl-3-sulfonamidopyrrolidines as novel inhibitors of cell division in Escherichia coli. Bioorganic \& Medicinal Chemistry Letters 17(23):6651-6655. DOI 10.1016/j.bmcl.2007.09.010.

Müller A, Wenzel M, Strahl H, Grein F, Saaki TN, Kohl B, Siersma T, Bandow JE, Sahl HG, and Schneider T. 2016. Daptomycin inhibits cell envelope synthesis by interfering with fluid membrane microdomains. Proceedings of the National Academy of Sciences 113(45):E7077-E7086. DOI 10.1073/pnas.1611173113.

Muthaiyan A, Silverman JA, Jayaswal RK, and Wilkinson BJ. 2008. Transcriptional profiling reveals that daptomycin induces the Staphylococcus aureus cell wall stress stimulon and genes responsive to membrane depolarization. Antimicrobial Agents and Chemotherapy 52(3):980-990. DOI 10.1128/AAC.01121-07.

Natarajan K, and Senapati S. 2013. Probing the conformational flexibility of monomeric FtsZ in GTP-bound, GDP-bound, and nucleotide-free states. Biochemistry 52(20):3543-3551. DOI 10.1021/bi400170f.

Ohashi Y, Chijiiwa Y, Suzuki K, Takahashi K, Nanamiya H, Sato T, Hosoya Y, Ochi K, and Kawamura F. 1999. The lethal effect of a benzamide derivative, 3methoxybenzamide, can be suppressed by mutations within a cell division gene, $f t s Z$, in Bacillus subtilis. Journal of Bacteriology 181(4):1348-1351.

Oliva MA, Trambaiolo D, and Löwe J. 2007. Structural insights into the conformational variability of FtsZ. Journal of Molecular Biology 373(5):1229-1242. DOI 10.1016/j.jmb.2007.08.056.

Pilhofer M, Ladinsky MS, McDowall AW, Petroni G, and Jensen GJ. 2011. Microtubules in bacteria: ancient tubulins build a five-protofilament homolog of the eukaryotic cytoskeleton. PLoS Biology 9(12):e1001213. DOI 10.1371/journal.pbio.1001213.

Pinho MG, Kjos M, and Veening J-W. 2013. How to get (a) round: Mechanisms controlling growth and division of coccoid bacteria. Nature Reviews Microbiology 11(9):601-614. DOI $10.1038 /$ nrmicro3088.

Poole K. 2012. Bacterial stress responses as determinants of antimicrobial resistance. Journal of Antimicrobial Chemotherapy:dks196. DOI 10.1093/jac/dks196. 
632 Qiu J, Wang D, Zhang Y, Dong J, Wang J, and Niu X. 2013. Molecular modeling reveals the

633

634

635

636

637

638

639

640

641

642

643

644

645

646

647

648

649

650

651

652

653

654

655

656

657

658

659

660

661

662 novel inhibition mechanism and binding mode of three natural compounds to staphylococcal $\quad \alpha$-hemolysin. $\quad P L O S \quad O N E \quad$ 8(11):e80197. DOI 10.1371/journal.pone.0080197.

Saeloh D, Tipmanee V, and Voravuthikunchai SP. 2016. Rhodomyrtone target exploration: Computer aided search on Staphylococcus aureus key proteins as a potential therapeutic target. Current Computer Aided Drug Design 12(2):119-134. DOI $10.2174 / 1573409912666160505112940$.

Salni D, Sargent MV, Skelton BW, Soediro I, Sutisna M, White AH, and Yulinah E. 2002. Rhodomyrtone, an antibotic from Rhodomyrtus tomentosa. Australian Journal of Chemistry 55(3):229-232. DOI 10.1071/CH01194.

Sass P, Josten M, Famulla K, Schiffer G, Sahl H-G, Hamoen L, and Brötz-Oesterhelt H. 2011. Antibiotic acyldepsipeptides activate ClpP peptidase to degrade the cell division protein FtsZ. Proceedings of the National Academy of Sciences 108(42):17474-17479. DOI 10.1073/pnas.1110385108.

Schaffner-Barbero C, Martín-Fontecha M, Chacón P, and Andreu JM. 2011. Targeting the assembly of bacterial cell division protein FtsZ with small molecules. ACS Chemical Biology 7(2):269-277. DOI 10.1021/cb2003626.

Sianglum W, Srimanote P, Taylor PW, Rosado H, and Voravuthikunchai SP. 2012. Transcriptome analysis of responses to rhodomyrtone in methicillin-resistant Staphylococcus aureus. PLoS ONE 7(9):e45744. DOI 10.1371/journal.pone.0045744.

Sianglum W, Srimanote P, Wonglumsom W, Kittiniyom K, and Voravuthikunchai SP. 2011. Proteome analyses of cellular proteins in methicillin-resistant Staphylococcus aureus treated with rhodomyrtone, a novel antibiotic candidate. PLOS ONE 6(2):e16628. DOI 10.1371/journal.pone.0016628.

Singh D, Bhattacharya A, Rai A, Dhaked HPS, Awasthi D, Ojima I, and Panda D. 2014. SB-RA-2001 inhibits bacterial proliferation by targeting FtsZ assembly. Biochemistry 53(18):2979-2992. DOI 10.1021/bi401356y.

Srinivasan J, Cheatham TE, Cieplak P, Kollman PA, and Case DA. 1998. Continuum solvent studies of the stability of DNA, RNA, and phosphoramidate-DNA helices. Journal of the American Chemical Society 120(37):9401-9409. DOI 10.1021/ja981844+. 
663 Stokes NR, Baker N, Bennett JM, Berry J, Collins I, Czaplewski LG, Logan A, Macdonald

664

665

666

667

668

669

670

671

672

673

674

675

676

677

678

679

680

681

682

683

684

685

686

687

688

R, MacLeod L, and Peasley H. 2013. An improved small-molecule inhibitor of FtsZ with superior in vitro potency, drug-like properties, and in vivo efficacy. Antimicrobial Agents and Chemotherapy 57(1):317-325. DOI 10.1128/AAC.01580-12.

Strahl H, and Hamoen LW. 2010. Membrane potential is important for bacterial cell division. Proceedings of the National Academy of Sciences 107(27):12281-12286. DOI 10.1073/pnas.1005485107.

Te Winkel JD, Gray DA, Seistrup KH, Hamoen LW, and Strahl H. 2016. Analysis of antimicrobial-triggered membrane depolarization using voltage sensitive dyes. Frontiers in Cell and Developmental Biology 4(29):1-10. DOI 10.3389/fcell.2016.00029.

Thompson MA. 2004. ArgusLab 4.0. 1. Planaria Software LLC, Seattle, WA.

Visutthi M, Srimanote P, and Voravuthikunchai SP. 2011. Responses in the expression of extracellular proteins in methicillin-resistant Staphylococcus aureus treated with rhodomyrtone. The Journal of Microbiology 49(6):956-964. DOI 10.1007/s12275-0111115-0.

Wang J, Hou T, and Xu X. 2006. Recent advances in free energy calculations with a combination of molecular mechanics and continuum models. Current Computer-Aided Drug Design 2(3):287-306. DOI 10.2174/157340906778226454.

Wang X, and Lutkenhaus J. 1993. The FtsZ protein of Bacillus subtilis is localized at the division site and has GTPase activity that is dependent upon FtsZ concentration. Molecular Microbiology 9(3):435-442. DOI 10.1111/j.1365-2958.1993.tb01705.x.

Weart RB, Nakano S, Lane BE, Zuber P, and Levin PA. 2005. The ClpX chaperone modulates assembly of the tubulin-like protein FtsZ. Molecular Microbiology 57(1):238249. DOI 10.1111/j.1365-2958.2005.04673.x. 
Figure 1

Rhodomyrtone structure:

(A) (S)-rhodomyrtone and (B) (R)-rhodomyrtone.

A<smiles>CC(C)CC(=O)c1c(O)cc2c(c1O)[C@H](CC(C)C)C1=C(O2)C(C)(C)C(=O)C(C)(C)C1=O</smiles>

(S)-rhodomyrtone<smiles>CC(C)CC(=O)c1c(O)cc2c(c1O)[C@H](CC(C)C)C1=C(O2)C(C)(C)C(=O)C(C)(C)C1=O</smiles>

(R)-rhodomyrtone 
Figure 2

C $\alpha$ root-mean-square distance ( $r m s d$ ) values of simulated FtsZ structures as a function of time.

Rmsds were calculated by superposing each snapshot on the starting structure to remove the rigid body translations and rotations. (A) Rmsds for total simulation time of $150 \mathrm{~ns}$. (B) Rmsds for last 50 ns of simulation.

A

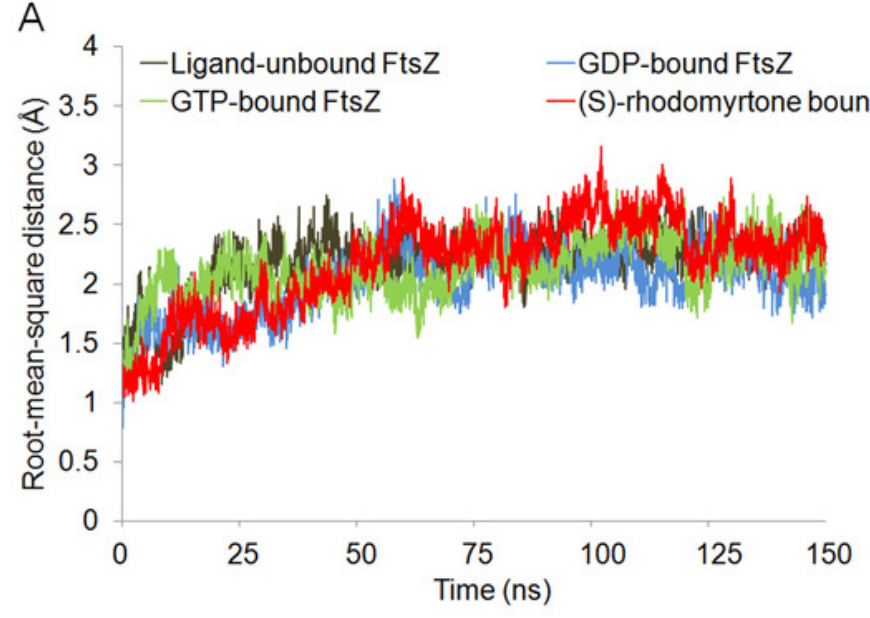

B

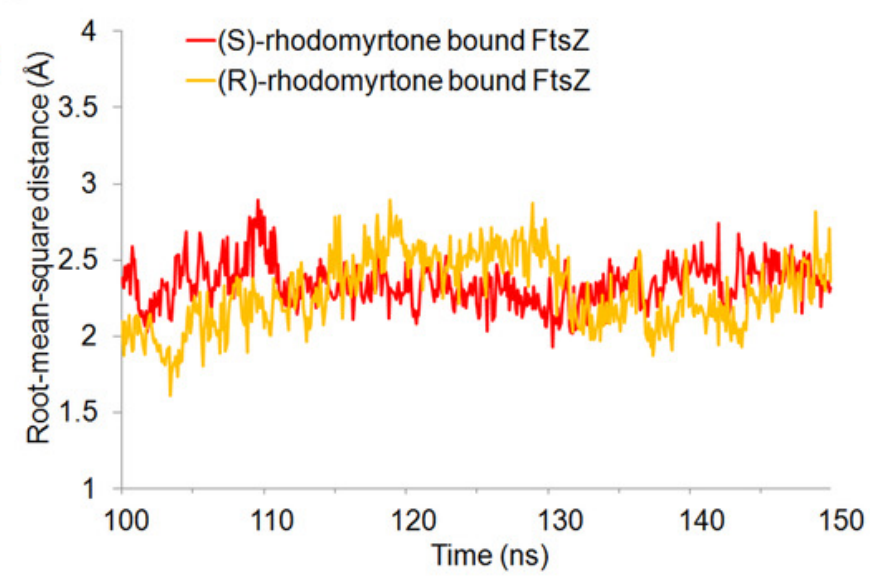


Figure 3

Average structures of each FtsZ state.

(A) The reference structure of FtsZ from PDB: 3VOA (Matsui et al., 2012) , (B) Ligand-free state of FtsZ: blue, (C) GDP-FtsZ complex: orange, (D) GTP-FtsZ complex: magenta, (E) (S)rhodomyrtone-FtsZ complex: red, (F) (R)-rhodomyrtone-FtsZ complex: pink.

A

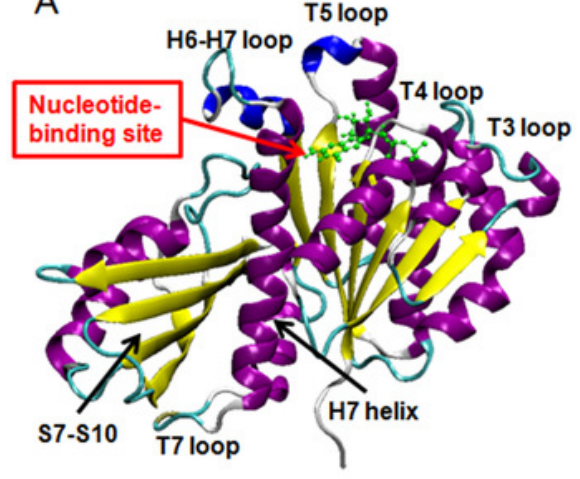

B

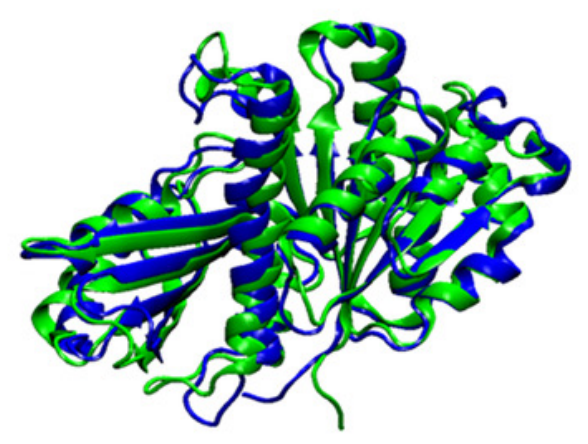

C

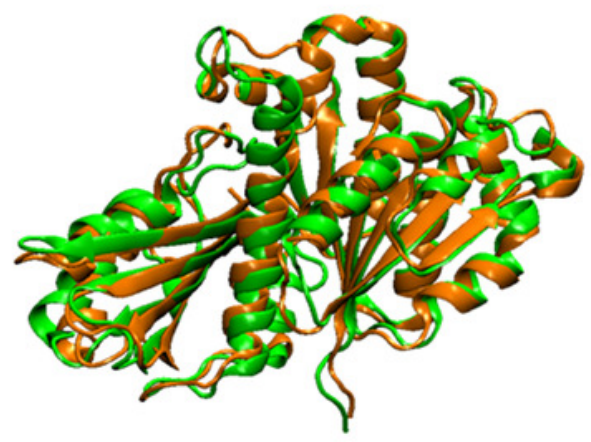

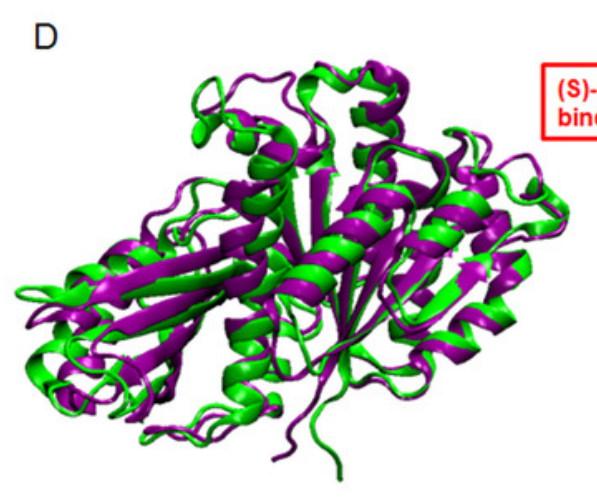

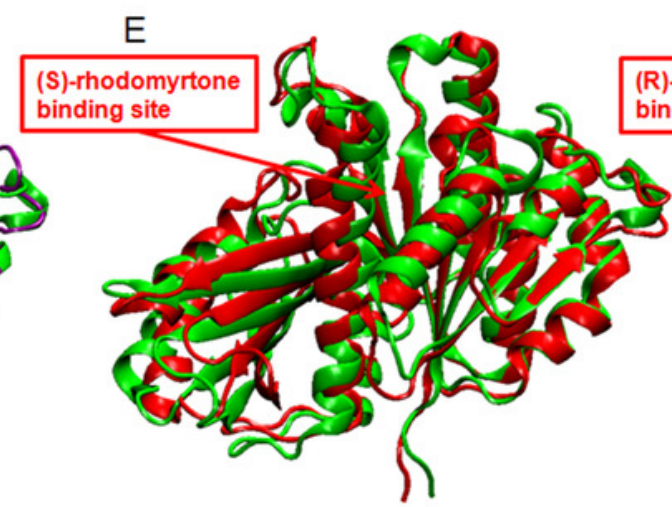

$\mathrm{F}$

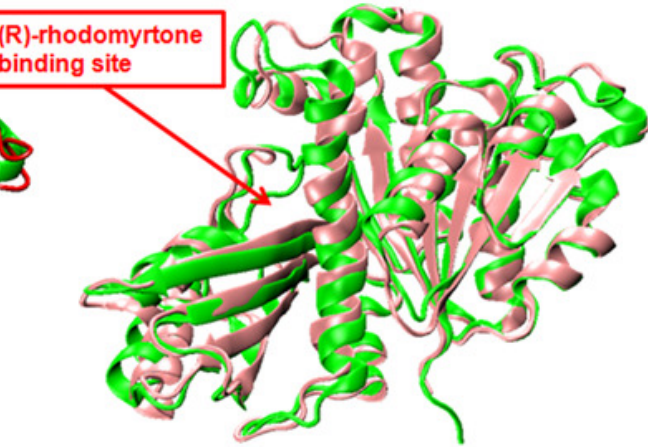




\section{Figure 4}

Structural model of rhodomyrtone-bound FtsZ.

(A) FtsZ crystal structure from S. aureus, PDB 3VOA, comprising two subdomains: (i) C-

terminal (nucleotide binding region) colored yellow, (ii) N-terminal (GTPase region) colored blue. (S)-rhodomyrtone is shown in red and (R)-rhodomyrtone in purple. (B) Residues of the protein within $3 \AA$ of (S)-rhodomyrtone. The structure of (S)-rhodomyrtone is rendered in balls and sticks and the atoms are colored according to their types: C-ice blue, O-red.

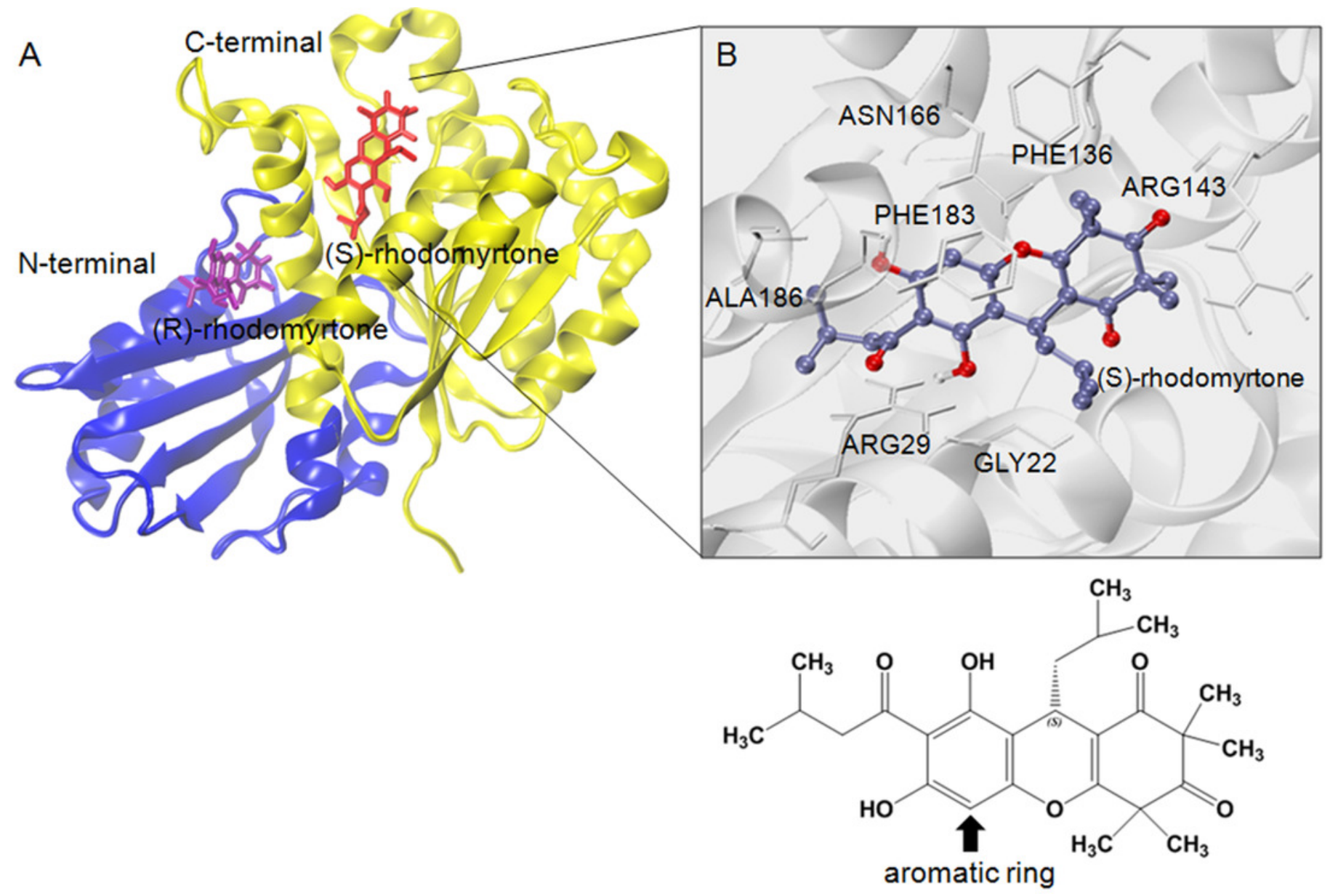


Figure 5

Fluctuations of FtsZ in four states of FtsZ depicted by root-mean-square-fluctuations (rmsf) of the $\mathrm{C}_{\alpha}$ atoms in three states of FtsZ monomer.

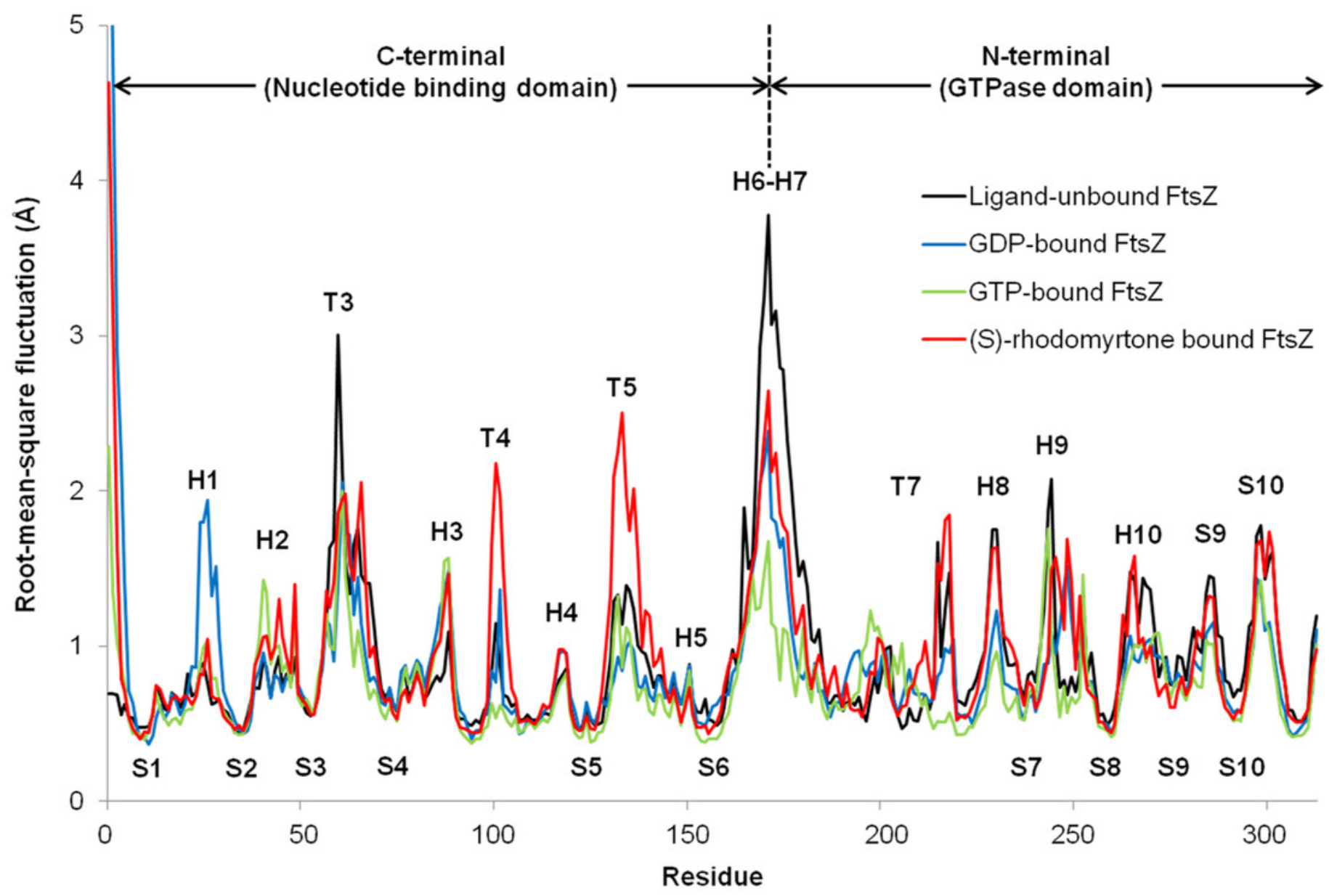




\section{Figure 6}

Effect of rhodomyrtone on FtsZ assembly in vitro.

(A) GTP-induced polymerization of purified FtsZ exposed to 1\% DMSO (a negative control), 10 $\mu \mathrm{M}$ rhodomyrtone, $20 \mu \mathrm{M}$ rhodomyrtone, and $20 \mathrm{mM}$ 3-MBA. The experiment was performed in triplicate and average spectra are shown. Error bars show standard errors of the mean. (B) Phase-contrast images of FtsZ bundles from the same samples.

A

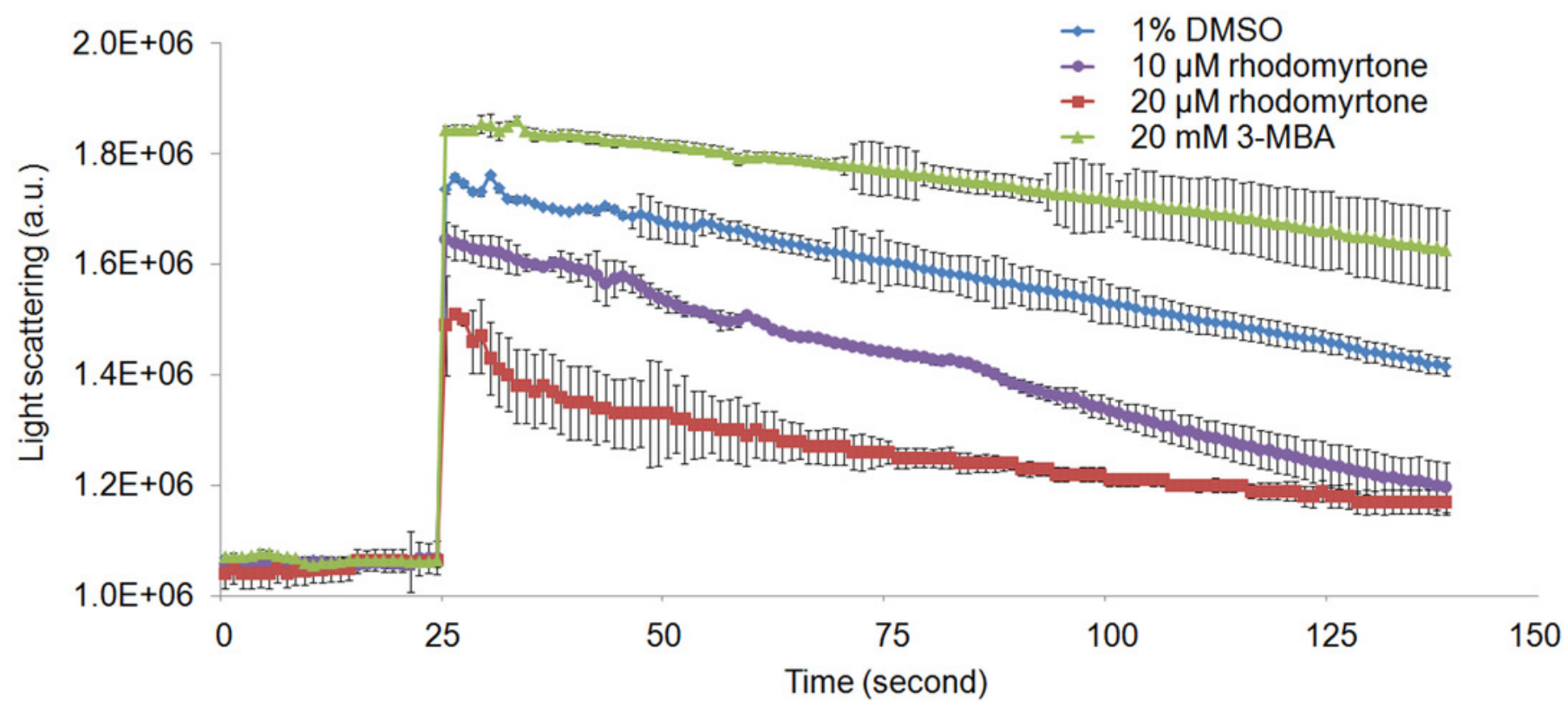

B

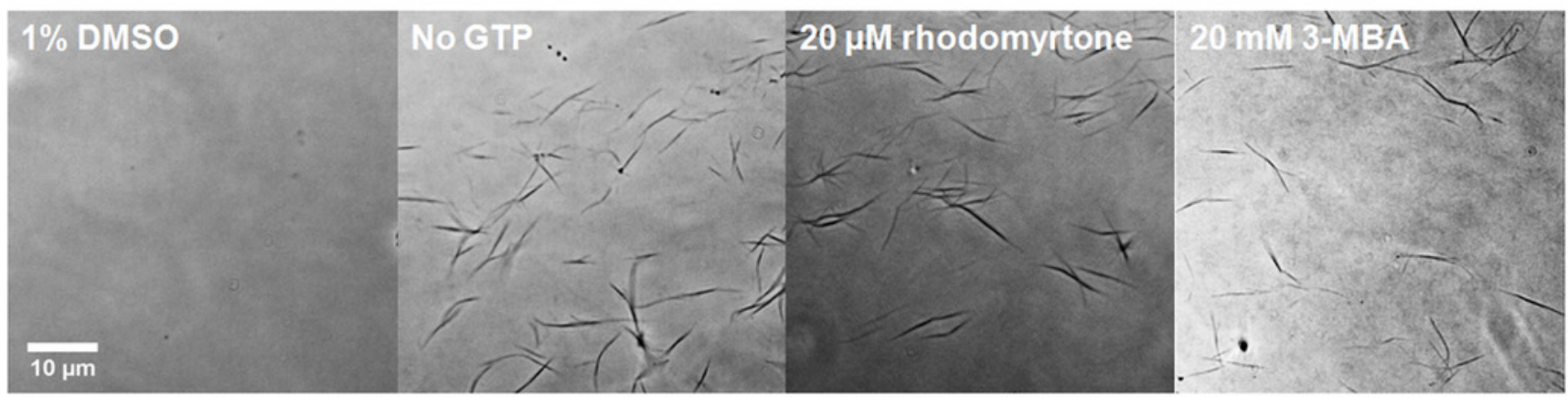




\section{Figure 7}

Effect of rhodomyrtone on the GTPase activity of purified FtsZ.

GTP hydrolysis was carried out in the presence of rhodomyrtone $(5,10$, and $20 \mu \mathrm{M})$ or 3-MBA $(5,10$, and $20 \mathrm{mM})$ by adding $1 \mathrm{mM}$ GTP. The cephalosporin cephalexin $(10 \mu \mathrm{M})$ was used as a negative control. The experiment was performed in triplicate. Error bars show standard errors of the mean.

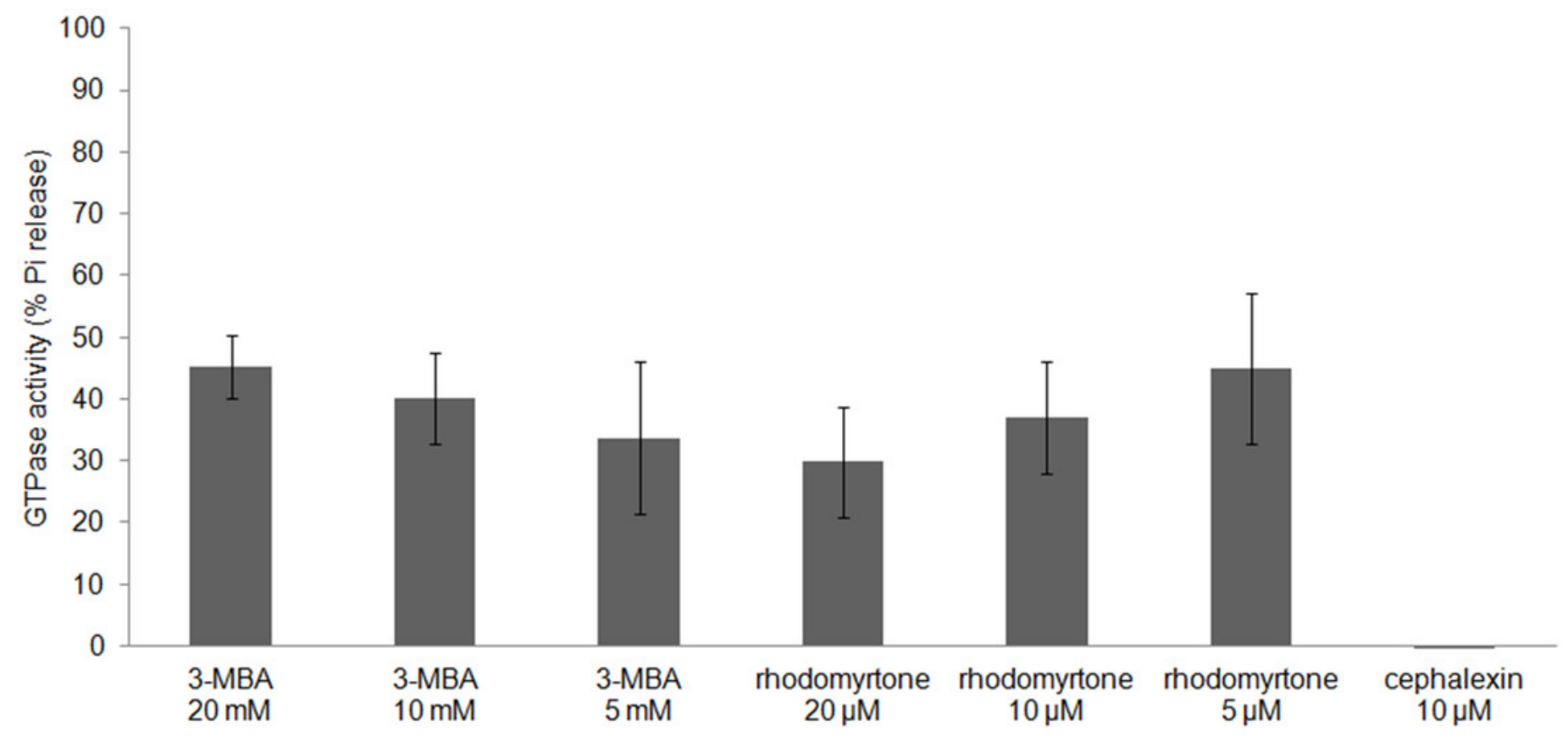




\section{Figure 8}

Effect of rhodomyrtone on FtsZ localization.

B. subtilis 874 expressing GFP-FtsZ was exposed to (A) 1\% DMSO for $30 \mathrm{~min}$, (B) 1\% DMSO for $60 \mathrm{~min},(C) 4 \times M I C$ of $3-M B A$ for $30 \mathrm{~min}$, (D) $4 \times$ MIC of 3-MBA for $60 \mathrm{~min}$. (E) 2xMIC of rhodomyrtone for $30 \mathrm{~min}$, (F) 2xMIC of rhodomyrtone for $60 \mathrm{~min},(\mathrm{G}) 4 \times \mathrm{MIC}$ of rhodomyrtone for $30 \mathrm{~min}$, and $(\mathrm{H}) 4 \times \mathrm{MIC}$ of rhodomyrtone for $60 \mathrm{~min}$.

*Note: Auto Gamma Correction was used for the image. This only affects the reviewing manuscript. See original source image if needed for review. 


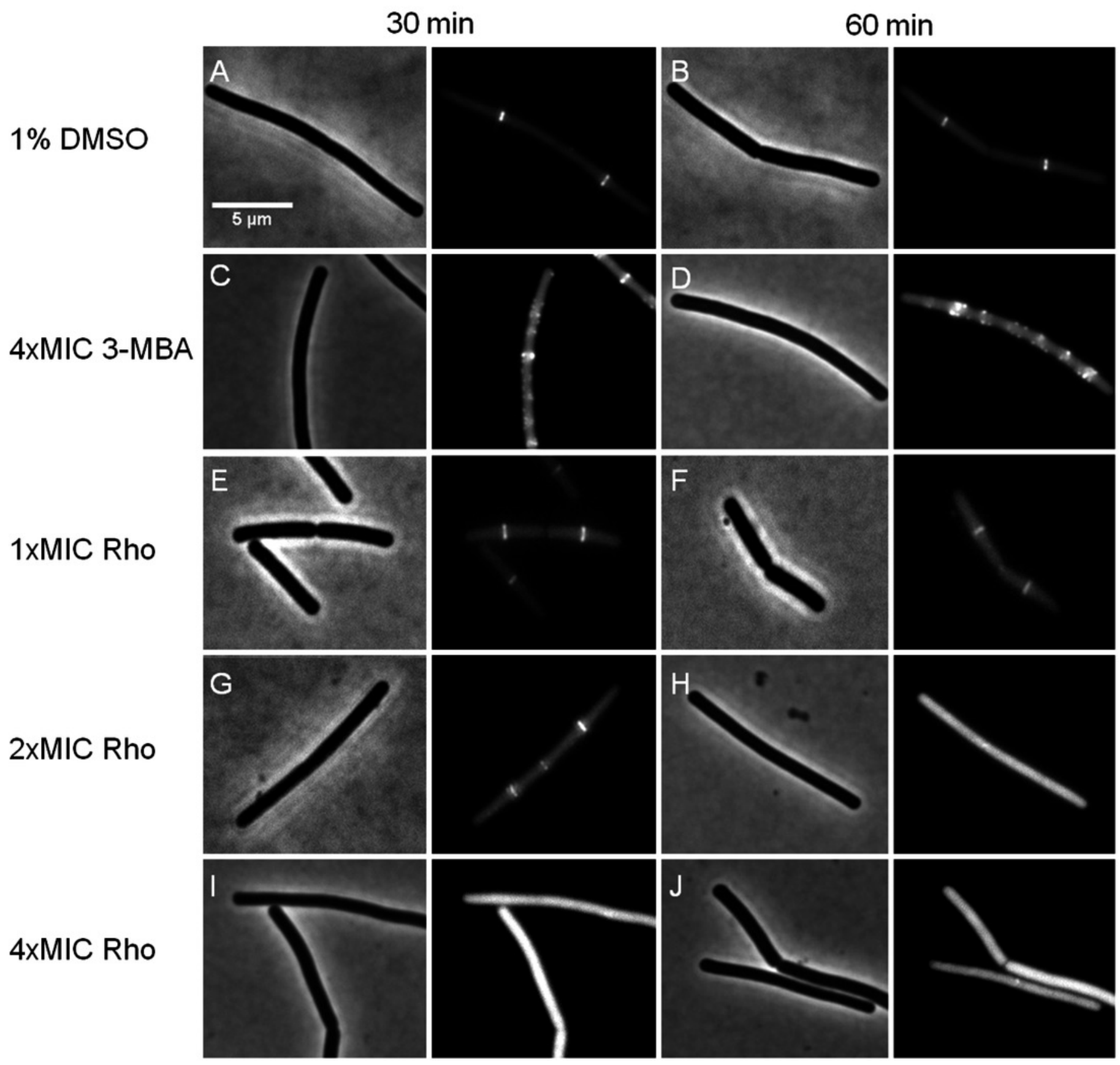




\section{Figure 9}

Localization of FtsZ and FtsA in comparison with CCCP.

B. subtilis 874 expressing GFP-FtsZ was exposed to (A) $1 \%$ DMSO for 10 min or (B) $100 \mu \mathrm{M}$ CCCP for 10 min. B. subtilis PG62 expressing YFP-FtsA was exposed to (C) 1\% DMSO for 10 min, (D) $100 \mu \mathrm{M}$ CCCP for $10 \mathrm{~min},(\mathrm{E}) 2 \times \mathrm{MIC}$ of rhodomyrtone for $30 \mathrm{~min}$, (F) 2xMIC of rhodomyrtone for $60 \mathrm{~min},(\mathrm{G}) 4 \times \mathrm{MIC}$ of rhodomyrtone for $30 \mathrm{~min}$, (H) 4xMIC of rhodomyrtone for $60 \mathrm{~min}$, (I) 4XMIC of 3-MBA for $30 \mathrm{~min}$, and (J) 4XMIC of 3-MBA for $60 \mathrm{~min}$.

*Note: Auto Gamma Correction was used for the image. This only affects the reviewing manuscript. See original source image if needed for review. 

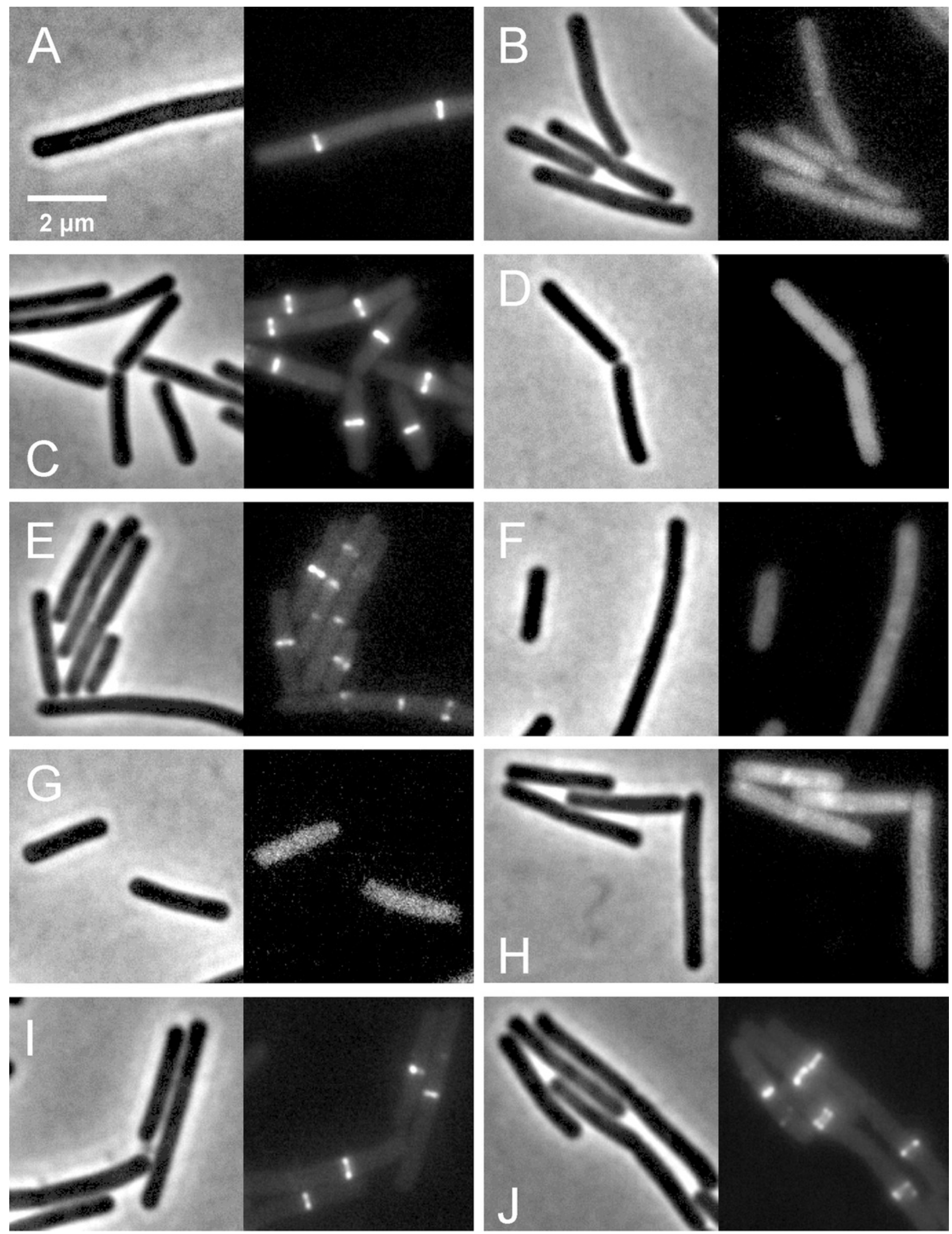


\section{Figure 10}

Localization of SepF.

B. subtilis 4181 expressing GFP-SepF was exposed to 1\% DMSO (negative control), $100 \mu \mathrm{M}$ CCCP, $2 \times$ MIC of rhodomyrtone, $4 \times$ MIC of rhodomyrtone, or $4 \times$ MIC of 3-MBA for 10 or 30 min, respectively.

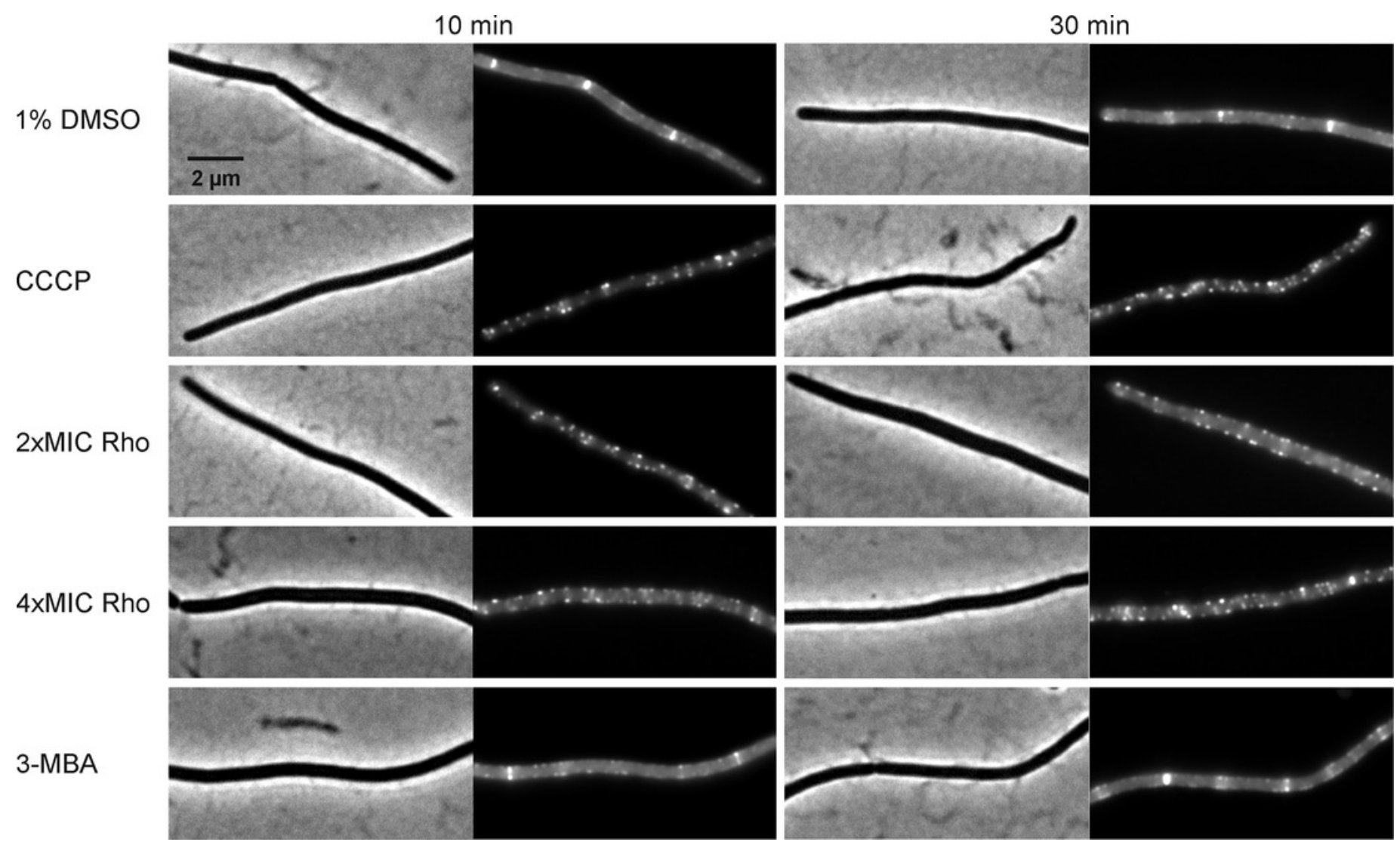




\section{Figure 11}

Cell morphology of Bacillus subtilis 168.

Cells were incubated with $1 \%$ DMSO (negative control), different concentrations of rhodomyrtone (1xMIC, $2 \times M I C$, and $4 \times$ MIC), and $4 \times$ MIC of 3-MBA. Pictures were taken after 1 h, 2 h, and 4 h. Phase-contrast images were obtained using an Olympus BX 50 microscope.

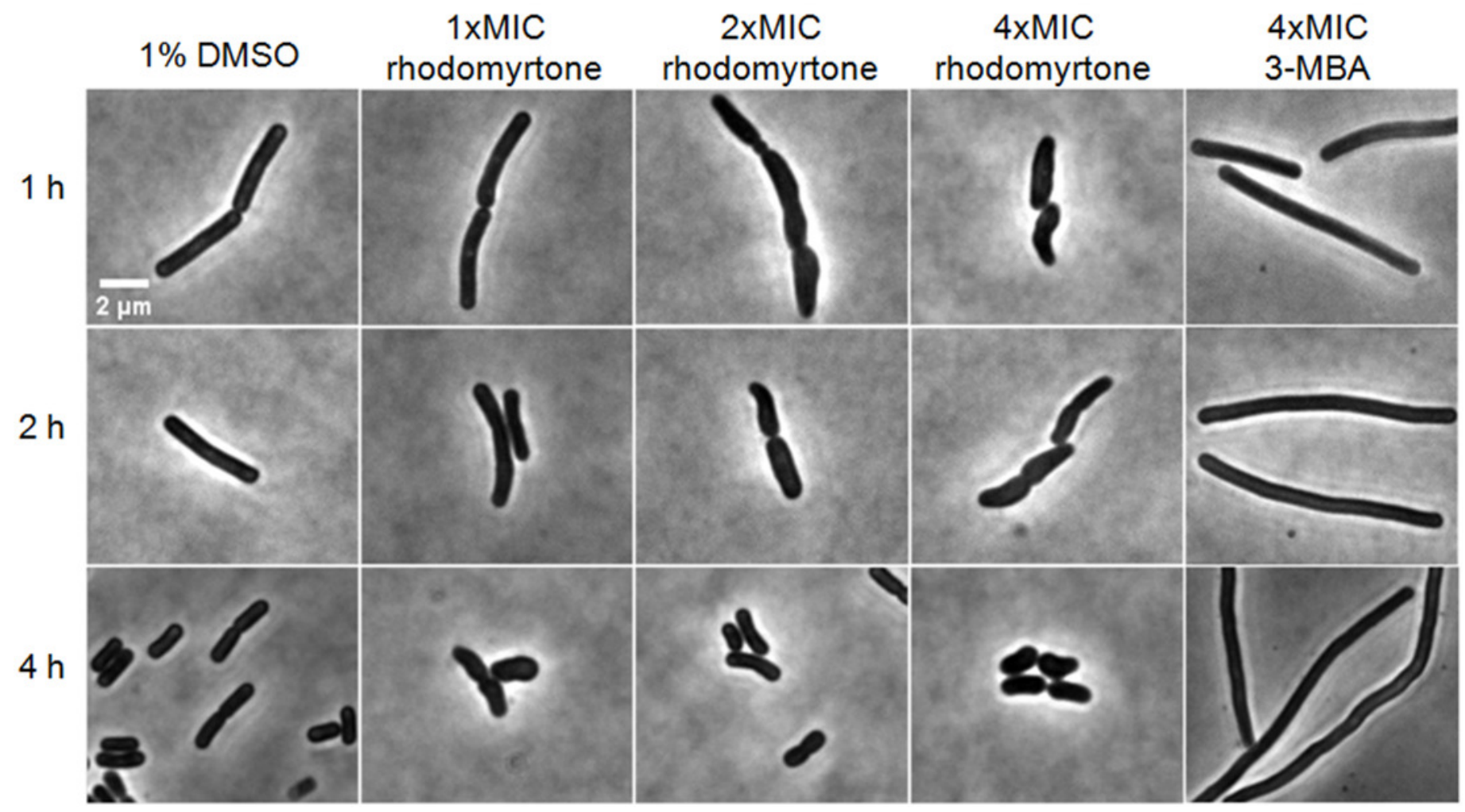




\section{Table 1 (on next page)}

Free energy components and total binding free energies $\left(\mathrm{kcal} \mathrm{mol}^{-1}\right)$. 


\begin{tabular}{llll}
\hline Compound & GDP & (S)-rhodomyrtone & (R)-rhodomyrtone \\
\hline$\Delta \mathrm{E}_{\text {van der Waal }}$ & $-40.41 \pm 0.20$ & $-45.48 \pm 0.12$ & $-29.04 \pm 3.30$ \\
$\Delta \mathrm{E}_{\text {electrostatic }}$ & $-171.55 \pm 1.26$ & $0.47 \pm 0.15$ & $-18.40 \pm 5.83$ \\
$\Delta \mathrm{G}_{\text {polar }}$ & $192.85 \pm 1.18$ & $20.69 \pm 0.15$ & $32.70 \pm 5.70$ \\
$\Delta \mathrm{G}_{\text {non-polar }}$ & $-4.51 \pm 0.01$ & $-4.26 \pm 0.01$ & $-3.37 \pm 0.25$ \\
\hline$\Delta \mathrm{G}_{\text {binding }}$ & $-23.61 \pm 0.33$ & $-35.92 \pm 0.36$ & $-18.11 \pm 3.67$ \\
\hline
\end{tabular}

1 


\section{Table 2 (on next page)}

The average cell length of $B$. subtilis cells in various times and treatments. 


\begin{tabular}{lccc}
\hline \multirow{2}{*}{ Compounds } & \multicolumn{3}{c}{ Cell length $(\mu \mathrm{m})^{\mathrm{a}}$} \\
\cline { 2 - 4 } & $1 \mathrm{~h}$ & $2 \mathrm{~h}$ & $4 \mathrm{~h}$ \\
\hline 1\% DMSO & $8.84 \pm 3.46$ & $9.12 \pm 5.46$ & $5.08 \pm 1.67$ \\
1xMIC rhodomyrtone & $8.88 \pm 5.10$ & $6.03 \pm 2.18$ & $4.56 \pm 1.35$ \\
2xMIC rhodomyrtone & $7.34 \pm 2.79$ & $5.55 \pm 3.61$ & $5.23 \pm 2.70$ \\
4xMIC rhodomyrtone & $6.67 \pm 3.15$ & $5.78 \pm 2.89$ & $4.44 \pm 2.17$ \\
4xMIC 3-MBA & $13.76 \pm 6.60$ & $30.30 \pm 12.00$ & $\mathrm{NA}$ \\
\hline
\end{tabular}

NA: not applicable

a: ImageJ was used to measure the cell length of 100 cells of each condition. 